\title{
EFEITO DA PROFUNDIDADE DE INCORPORAÇÃO NO SOLO DE HERBICIDAS RESIDUAIS NA CULTURA DA SOJA (Glycine max (L.) MERRILL)
}

\author{
ANDRÉ LUIZ MELHORANÇA
}

Orientador: Prof. Dr. RICARDO VICTÓRIA FLLHO

Dissertação apresentada à Escola Superior de Agricultura "Luiz de Queiroz", da Universidade de São Paulo, para obtenção do Título de Mestre em Fitotecnia.

$P \mid R A C I C A B A$

Estado de São Paulo - Brasil

Fevereiro - 1982 
ii

$\overline{\mathrm{A}}$ minha esposa, Marli

e aos meus filhos Andrē,

Erica e Ellen

DEDICO . 


\section{AGRADECIMENTOS}

o autor deseja manifestar os seus mais profundos e sinceros agradecimentos a todos que direta ou indiretamente contribuiram para que este trabalho pudesse ser realiza do, e em especial às seguintes pessoas e instituições:

- Ao Prof. Dr. Ricardo Victória Filho pela ami zade, estímulo e preciosa orientação no transcorrer das fases deste trabalho;

- À Empresa Brasileira de Pesquisa Agropecuária (EMBRAPA) pela oportunidade de treinamento a nível de PósGraduação;

- Aos professores do Departamento de Agricultu ra e Horticultura da ESALQ, pela amizade, esforço e dedicação na formação científica;

- Ao Engo Agro Marcio Antonio Mastrocola, pela amizade, apoio e estímulo, desde o início do curso de pós-Gra duação até a apresentação desta;

- Aos funcionários da Biblioteca/ESALQ, em es-

pecial ao Sr. Luiz Carlos Veríssimo e Sra. Maria Elisabeth Fer reira de Carvalho pela colaboração.

- Aos Técnicos Agrícolas Antonio de Oliveira Duarte e Julio Leal pela colaboração na instalação do experimento a campo. 
LISTA DE TABELAS..................... v

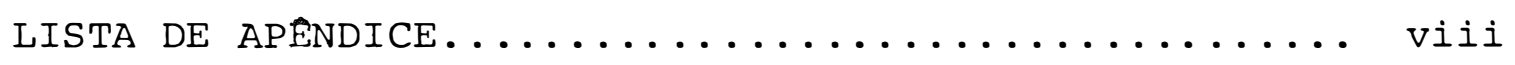

RESUMO ........................ ix

SUMMARY................................

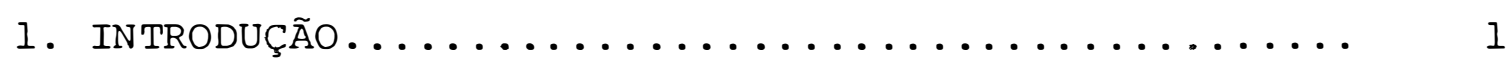

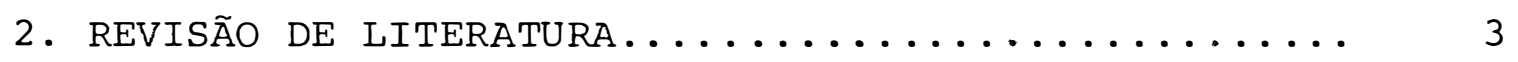

2.1. Profundidade de incorporação de trifluralin no solo e seus efeitos na planta........... 4

2.2. Profundidade de incorporação de metribuzin no

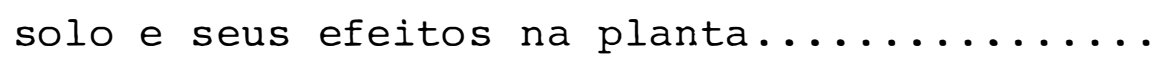

2.3. Profundidade de incorporação de vernolate no solo e seus efeitos na planta............ 10

2.4. Profundidade de incorporação de pendimethalin no solo e seus efeitos na planta........... 12

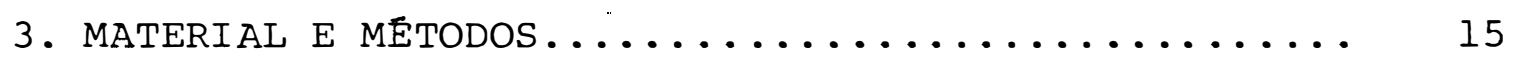

3.1. Experimento de campo................. 15

3.2. Experimento em casa-de-vegetação.......... 20

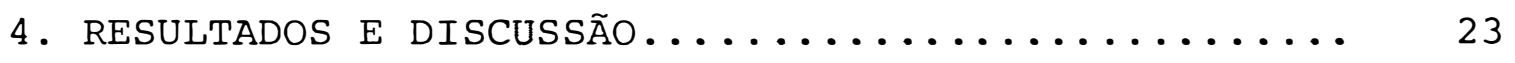

4.1. Experimento de campo................. 23

4.2. Experimento em casa-de-vegetação.......... 34

5. CONCLUSÕES ............................ 51

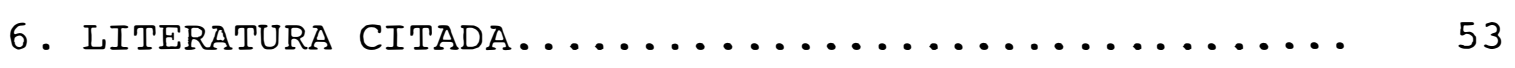

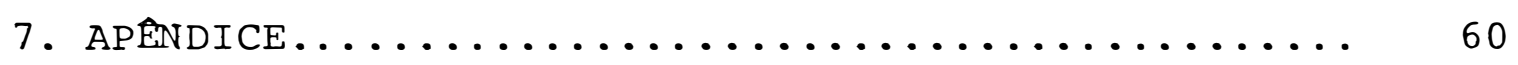


01 Características químicas e físicas do solo onde foi instalado o experimento (Dourados , MS, 1981).......................

02 Esquema das análises de variância, dos dados obtidos, nas determinações do experi -

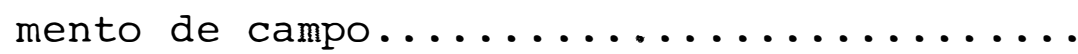

03 Esquema das análises de variância, dos dados obtidos, nas determinações efetuadas em

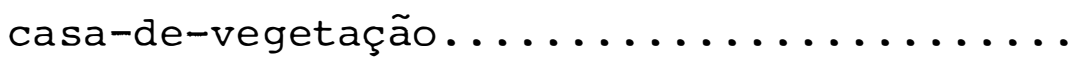

04 Médias de produção em kg/parcela, peso (g) de grãos por planta, número de grãos por planta, número de vagens por planta e peso (g) de 100 grãos para os tratamentos e para as profundidades de incorporação (Doura

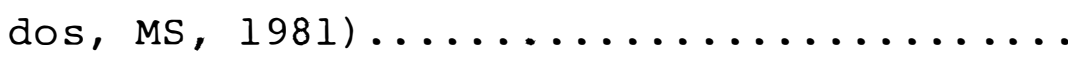

05 Médias da altura (cm) de planta aos 15, 30 e 60 dias após a emergência e na colheita, e altura (cm) de inserção da primeira vagem, para os tratamentos e para as profundidades de incorporação (Dourados, MS, 1981).

06 Médias da população inicial e final, número de ramificações por planta e peso (g) da matéria seca das plantas daninhas, para tra tamentos e para profundidades de incorpora ção (Dourados, MS, 1981).............. 
07 Médias das interações entre tratamentos e profundidades de incorporação sobre a popu lação inicial de plantas de soja - número de plantas em $8 \mathrm{~m}^{2}$ (Dourados, MS, 1981)...

08 Médias das interações entre tratamentos e profundidades de incorporação sobre a popu lação final de plantas de soja número de plantas em $8 \mathrm{~m}^{2}$ (Dourados, MS, 1981).....

09 Médias da altura (cm) de plantas aos 7 e 15 dias após a emergência, e peso (g) da matê ria seca da parte aérea e radicular aos 15 dias após a emergência, para tratamentos

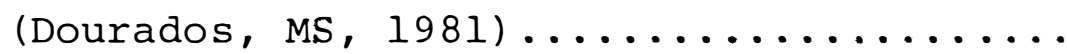

10 Interação entre tratamentos e cultivaresso bre a média de altura (cm) de planta de so ja aos 7 dias após emergência (Dourados,Ms,

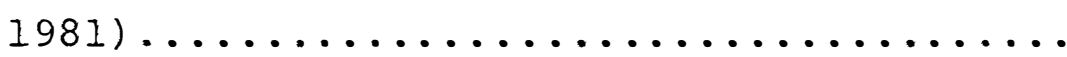

11 Interação entre tratamentos e profundida des de incorporação, sobre a média da altú ra (cm) de planta aos 7 dias após a emer gência da soja (Dourados, MS, 1981)......

12 Interação entre tratamentos e cultivares , sobre a média de altura (cm) das plantas aos 15 dias após a emergência da soja (Dou rados, $M S, 1981) \ldots \ldots \ldots \ldots \ldots \ldots \ldots \ldots . . \ldots$ 
13 Interação entre tratamentos e profundidades de incorporação, sobre a média da altura (cm) de plantas aos 15 dias após a emergência da

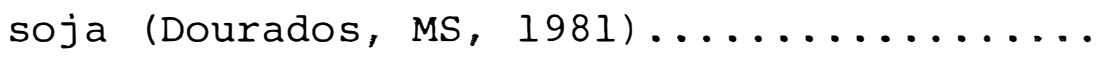

14 Interação entre tratamentos e cultivares so bre a média de peso (g) da matéria seca das raízes aos 15 dias após a emergência da so-

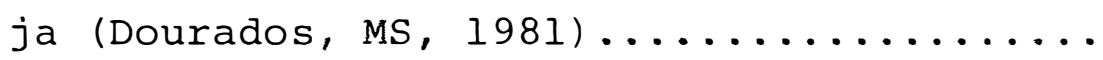

15 Interação entre tratamentos e profundidades de incorporação, sobre a média de peso (g) da matēria seca de raízes aos 15 dias após a emergência da soja (Dourados, MS, 1981)..

16 Interação entre tratamentos e cultivares, so bre a média do peso (g) da matéria seca da parte aérea da soja aos 15 dias após emer gência (Dourados, MS, 1981).............

17 Interação entre tratamentos e profundidades de incorporação, sobre a média de peso (g) da matéria seca da parte aērea da soja aos 15 dias após a emergência (Dourados, MS, 1981). 


\section{LISTA DE APENDICE}

TABELA

Página

18 Dados meteorológicos diários do mês de de-

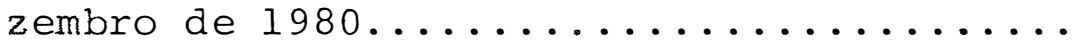

19 Dados meteorológicos diários do mês de ja-

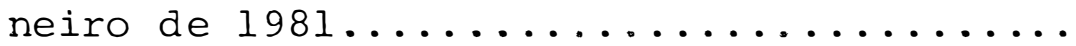

20 Dados meteorológicos diários do mês de fevereiro de $1981 \ldots \ldots \ldots \ldots \ldots \ldots \ldots \ldots \ldots \ldots \ldots$

21 Dados meteorológicos diārios do mês de mar

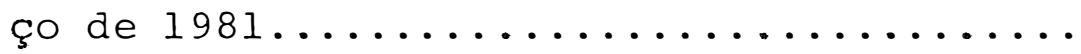




\section{EFEITO DA PROFUNDIDADE DE INCORPORAÇÃO NO SOLO DE HERBICIDAS RESIDUAIS NA CULTURA DA SOJA | glycine max (L.) MERRILLI}

André Luiz Melhorança Orientador: Prof. Dr. Ricardo Victória Filho

\section{RESUMO}

A presente pesquisa foi conduzida no município de Dourados, MS, no ano agrícola de 1980/81 com o objetí vo de avaliar o efeito da profundidade de incorporação dos principais herbicidas usados na cultura da soja. Para tanto foram instalados dois experimentos, sendo um a campo e outro em vasos, em casa-de-vegetação. Os herbicidas utilizados foram trifluralin, metribuzin, vernolate e pendimethalin, nas doses respectivas de $1,11,0,36,3,86 \mathrm{e} 1,50 \mathrm{~kg}$ i.a/ha, incorporados ao solo às profundidades de 0, 2,5, 5,0 e 10,0 cm, sendo semeada a cultivar de soja 'Paraná' no experimento de campo, e as cultivares Bossier, Santa Rosa e Paraná na casa-de-vegetação.

A avaliação dos resultados foi realizada cole tando-se dados de altura de plantas, população inicial e final, peso da matéria seca de plantas daninhas e dados de pro 
dução apresentada pela soja nos diferentes tratamentos, sendo observado que em condições de campo a profundidade de incorpo ração não afetou o desenvolvimento e produção da soja, nem tão pouco, o controle das plantas daninhas, expresso pelo seu peso da matéria seca. Entretanto, em condições de casa-de-vegetação a profundidade de incorporação afetou o peso da matéria seca da parte aérea e radicular, e a altura das plantas. A altura e peso da matéria seca da parte aérea foi mais afeta da pelo vernolate quando incorporado a $10 \mathrm{~cm}$. Trifluralin incorporado a $10 \mathrm{~cm}$, e pendimethalin aplicado à superfície também afetaram em menor intensidade. O sistema radicular foi mais afetado pelo pendimethalin e vernolate. A cultivar santa Rosa, foi a que se mostrou mais sensivel aos herbicidas utili zados. 


\section{EFFECT OF INCORPORATION DEPTH \\ OF RESIDUAL HERBICIDES IN SOYBEAN \\ Grycine max (L.) MERRILL}

Author: André Luiz Melhorança

Adviser: Ricardo Victória Filho

\section{SUMMARY}

The present research was developed at Dourados, Mato Grosso do Sul State, Brazil, in the agricultural year of 1980-1981 with the aim of evaluating the effect of the incorporation depth of the main herbicides used in soybean. Therefore two experiments have been conducted, being one in the field and the other in pots at greenhouse.

Herbicides have been utilized are trifluralin, metribuzin, vernolate and pendimethalin in respective doses of $1.11,0.36,3.86$ and $1.50 \mathrm{~kg}$ a.i/ha incorporated to the soil at depth of $0,2.5,5.0$ and $10.0 \mathrm{~cm}$, being sown the variety of Parana soybean in the field experiment, and Bossier, Santa Rosa and Paraná varieties in the greenhouse.

The assessment of results has been carried out by collecting data of plants height, initial and final popula 
tion, and weeds dry matter weigh and production data presented by soybean at different applications, being observed that for field conditions, incorporation depth has not affected soybean development and production, expressed by its dry matter weigh. However, at greenhouse conditions, incorporation depth has affected dry matter weigh in the aerial and radicular part and plants height. Aerial part height and dry matter weigh have been more affected by vernolate when incorporated at 10 $\mathrm{cm}$. Trifluralin incorporated at $10 \mathrm{~cm}$ and pendimethalin applied at the surface have affected at a lower intensity as well. The radicular system has been more affected by both pendimethalin and vernolate. The santa Rosa variety has been the one that showed itself mos sensitive to the utilized herbicides. 


\section{INTRODUÇÃO}

Dentre as principais dificuldades com que o agricultor se defronta no sentido de obter melhores indices de produtividade na cultura da soja, destaca-se a concorrência que as plantas daninhas exercem na cultura, em água, luz e nutrientes.

A cultura è explorada extensivamente, tornan do-se impraticável o controle manual, e aliado ao fato do con trole mecânico geralmente não atingir a eficiência desejada,

o uso de herbicidas tornou-se uma prática rotineira no cultivo desta leguminosa.

Sabe-se, hoje, que aproximadamente $30 \%$ do volu me físico dos herbicidas comercializado na agricultura do País, são aplicados na cultura da soja, numa média de cerca de 1,5 litros por hectare, segundo dados BRASII (1979).

E evidente que essa tecnologia onera substan- 
cialmente a rentabilidade líquida das lavouras, e além disso, - controle quịmico é um método, que exige conhecimentos básicos e um nivel educacional adequado do agricultor. Isto para que sejam evitados os efeitos negativos que possam ocorrer no solo, na planta e na própria produtividade da cultura.

A presente pesquisa foi planejada e conduzida com a finalidade principal de avaliar os efeitos da profundi dade de incorporação no solo de herbicidas sobre o desenvolvimento e produção, observando os possíveis efeitos fitotóxicos na cultura da soja. 


\section{REVISÃO DE LITERATURA}

O uso adequado dos herbicidas como método de controle químico das plantas daninhas exige que também sejam conhecidos os seus efeitos na planta e no solo. Os principais efeitos do tri fluralin, metribuzin, vernolate e pendimethalin sobre o desen volvimento, a produção e a tolerância da soja são aqui relatạ dos, bem como a importância da profundidade de incorporação, pois segundo PARKER (1966), um dos principais fatores que influenciam a atividade dos herbicidas é a colocação numa pro fundidade correta, pois dela depende a absorção pela região mais ativa da planta (caulículo ou radícula).

As plantas daninhas competem com a soja em água, luz e nutrientes, e quando não controladas causam sérios prejuízos à produção como mostram os trabalhos de KNAKE e SLI FE (1965) e MOOLANI et alii (1964) onde a concorrência das plantas daninhas causaram redução em 27 e 55\%, respectivamente. 


\subsection{Profundidade de incorporação de trifluralin no solo E SEUS EFEITOS NA PLANTA}

HICKS e FLETCHALL (1964) em estudos sobre o po sicionamento de trifluralin no solo, concluíram que é perigoso incorporar trifluralin a profundidades superiores àquelas onde estão colocadas as sementes de soja, especialmente quando as condições ambientais limitam o crescimento das plantas, isto porque a plântula em desenvolvimento permaneceria mais tempo em contato com a zona tratada pelo herbicida.

STANDIFER e TOMAS (1965) em Louisiana, E.U.A., realizaram uma pesquisa para verificar o comportamento do algodão e do capim-maçambará |Sorghum halepense (L.) Pers.| ao trifluralin incorporado a diferentes profundidades. Para 0 al godão plantado a $2,5 \mathrm{~cm}$ de profundidade, verificaram que não havia formação de raízes laterais quando a raiz primária estava em contato com a zona tratada. Trifluralin foi incorporado a profundidades de $2,5,5,0,7,5,10,0$ e $12,5 \mathrm{~cm}$. As observa ções de campo, mostraram todavia que as plantas recuperaram dos efeitos de trifluralin e que raramente ocorria redução na produção. Com relação ao capim-maçambará, um controle consistente somente foi obtido em plantas oriundas de sementes, quan do trifluralin foi incorporado em pequena profundidade. Este resultado está em concordância com o obtido por KNAKE et alii (1967), em Oregon, E.U.A., que afirmam que trifluralin é mais eficiente quando colocado na faixa de solo acima das sementes. 
Trabalhando com trifluralin, em diversas concentrações, NEGI e FUNDERBURK (1967) em Alabama, E.U.A., veri ficaram que nas concentrações de 10 e 15 ppm causaram inibição no crescimento das plantas de soja que sobreviveram em to dos os tratamentos mas apresentaram a nodulação e o crescimen to das raizes afetado.

OLIVER e FRANS (1968) em Arkansas, E.U.A., mos traram que trifluralin incorporado a diferentes profundidades apresentou uma redução maior no nümero de raízes laterais da soja, quando incorporado a $5 \mathrm{~cm}$, ou seja, um pouco abaixo da profundidade de plantio. Quando incorporado a profundidades maiores, ou apenas acima da semente da soja, os danos foram minimos. Por outro lado, se a inibição não é suficiente para causar morte da plântula, então pode haver um efeito compensa tivo, onde a planta produziria maior número de raízes laterais, quando deixasse a zona tratada pelo trifluralin.

$$
\text { ESPINOZA et alii (1968) em Minnesota, E.U.A., }
$$

estudando os efeitos de trifluralin sobre o crescimento da so ja, concluíram que trifluralin contribuiu para o atraso na emergência da soja, aumentando a suscetibilidade das plântulas ao "damping-off" e severas injūrias ocorreram na soja em tratamentos contendo 4,5 ppm do ingrediente ativo.

KUST e STRUCKMEYER (1971) em Wisconsin, E.U.A., verificaram que incorporação de trifluralin a $10 \mathrm{~cm}$, reduziu o crescimento da parte aérea, mas o posicionamento do trifluralin não afetou o crescimento das raízes. o peso de matéria 
seca da parte aérea foi reduzido significativamente, com o au mento da dose do herbicida. Os efeitos no peso da matéria seca da parte aérea foram mais pronunciados, quando trifluralin foi incorporado de 5 a $15 \mathrm{~cm}$, do que quando incorporado nos $5 \mathrm{~cm}$ superficiais.

PAULA (1972) no Brasil, cita que quando trifluralin foi incorporado ás profundidades de 5 a $15 \mathrm{~cm}$, afetou o sistema radicular, inibiu a utilização das reservas cotiledonares e cau sou efeitos negativos sobre a nodulação das plantas de soja, havendo diminuição do número e peso dos mesmos.

DEPETRIS (1976) em Córdoba, Argentina, estudan do o efeito de distintas concentrações de trifluralin, assim como a profundidade de incorporação, verificou que quando incorporado a $10 \mathrm{~cm}$ ocorria uma redução de 16\% no peso fresco das raízes a $0,75 \mathrm{ppm}$, e $20 \%$ a $1,5 \mathrm{ppm}$. Por outro lado, uma incorporação a $3 \mathrm{~cm}$, ou seja, acima da semente, na concentração de 1,5 ppm não apresentou danos ao sistema radicular. DAVIS et alii (1976) na Carolina do Sul,E.U.A., realizaram alguns experimentos aplicando trifluralin e dini tramine em posições estabelecidas no perfil do solo, onde plantaram algodão e soja. Os resultados mostraram o efeito mais negativo, medido através da germinação, altura de plantas aos 5 e 12 dias, e peso verde aos 12 dias, foi quando os herbicidas foram colocados na mesma profundidade das sementes. O tri fluralin foi aplicado na dose de $1,15 \mathrm{~kg}$ i.a/ha e dinitramine a $0,72 \mathrm{~kg} \mathrm{i.a/ha}$. 


\subsection{Profundidade de incorporação de metribuzin no solo e SEUS EFEITOS NA PLANTA}

COBLE e SCHRADER (1973) na Carolina do Norte, E.U.A., verificaram que as doses do herbicida, matéria orgânica e chuva após a aplicação influenciam a tolerância da soja ao metribuzin. o estudo indicou que a tolerância da soja é mais devido à posição da semente no solo, do que fisiológica. Injūrias severas foram observadas quando o teor de matéria orgânica era de 1,1\%. HARDCASTLE et alii (1974), na Georgia, E.U.A., trabalhando com as cultivares Bragg, Coker 318 , Cokex 102, Hardee, Hampton e Bienville, verificaram que metribuzin reduziu significativamente a altura, população e rendimento da Coker 102, não afetando substancialmente as outras cultivares. Explicam o fato pelo metabolismo diferencial das plântulas de cada cultivar ao metribuzin.

HARGRODER e ROGERS (1974) na Louisiana,E.U.A., em trabalho similar acrescentam que diferenças na absorção, translocação, além do metabolismo diferencial, parecem contri buir para uma diferencial suscetibilidade das cultivares de soja ao metribuzin.

CRAWFORD e ROGERS (1975) na Louisiana, E.U.A.,

realizaram diversos experimentos, utilizando metribuzin a $0,42,0,56$ e $0,84 \mathrm{~kg}$ i.a./ha, ou na dose de 0,56 em associação com dinitroanilinas. Quando ocorreu precipitações adequadas a pōs a aplicação, o comportamento do metribuzin foi o mesmo 
tanto em pré-emergência ou incorporado. Nenhuma das doses uti lizadas apresentou problema de fitotoxidade à soja.

MCCUTCHEN et alii (1975) no Tennessee, E.U.A., con duziram diversos experimentos com metribuzin a 0,42 e 0,56 kg i.a./ha, aplicado isoladamente ou em misturas com dinitroanilinas em pré-emergência e em pré-plantio incorporado. Metri buzin incorporado apresentou melhores resultados de controle porém com maior injúria à soja.

Segundo HONDA et alii (1976) no Paraná, BR, metribuzin a $0,63 \mathrm{~kg}$ i.a./ha em pré-emergência, aplicado na sụ perfície do solo mostrou sintomas de injūrias mais evidentes, inclusive com redução do número de plantas por metro linear , do que quando incorporado ao solo antes do plantio. Como injū rias foi observado a queima das bordas das primeiras folhas, que posteriormente se recuperaram completamente.

LORENZI (1976) no Paraná, BR, utilizando doses crescentes de metribuzin na cultivar Viçoja, concluiu que não foi verificado nenhum sintoma de injūria, bem como não houve variação do número de plantas 15 dias após a germina ção, e também não sendo observado qualquer prejuízo na produção de grãos mesmo quando metribuzin foi usado a 1,0 kg i.a./ ha, precedido de 0,96 kg i.a./ha de trifluralin.

Um fator importante a ser considerado na utili zação do metribuzin é a existência de diferentes sensibilidades das cultivares de soja a este herbicida, pois WAX et alii (1976), em Illinois, E.U.A., avaliando respostas de aproxima- 
damente 250 cultivares para metribuzin incorporado no solo, em experimento de campo, verificaram que a maioria das culti vares foram relativamente tolerantes ao metribuzin a $0,56 \mathrm{~kg}$ i.a.ha. A 0,84 e $1,7 \mathrm{~kg}$ i.a./ha a maior parte das cultivares fo ram severamente injuriadas ou mortas. Algumas das cultivares mais sensiveis foram Altona, Normam, Portage, Semmer, Tracy e Vansoy .

WAX (1977), em Illinois, E.U.A., trabalhando

com a cultivar 'William' e metribuzin, a $0,0,56$ e $0,84 \mathrm{~kg}$ i.al ha nas profundidades de incorporação de $0,2,5,5,1$ e 7,6 cm, em um solo contendo 5,5\% de matéria orgânica, verificou um au mento do controle das plantas daninhas presentes com o aumento da dose de 0,56 para $0,85 \mathrm{~kg}$ i.a.ha. O aumento da profundi dade de incorporação de 0 para $7,6 \mathrm{~cm}$ aumentou o controle, mas com leves injūrias na soja. A falta de chuva 10 dias após a a plicação diminuiu o controle de algumas espécies, todavia o controle permanecia se metribuzin fosse incorporado a pelo me nos $5,1 \mathrm{~cm}$. Metribuzin a $1,12 \mathrm{~kg} \mathrm{i.a/ha} \mathrm{incorporado} \mathrm{apresen-}$ ta severas injúrias com redução na produção.

VELLOSO e FLECK (1980), no Rio Grande do Sul, BR, com o objetivo de avaliar o comportamento de sete cultiva res de soja em respostas a épocas de aplicação do herbicida metribuzin na dose de $0,49 \mathrm{~kg}$ i.a./ha, constataram que o trata mento em pré-semeadura incorporado foi o que ocasionou maior efeito fitotóxico, enquanto que as de pré-emergência e pós-emergência em superfície apresentaram menor grau de injürias. 
o número de grãos por plantas foi o principal fator responsāvel pelas diferenças verificadas no rendimento. As cultiva res Paraná, Planalto e IAS-5 foram as que mais reduziram a população quando metribuzin foi aplicado incorporado.

BRAZ et alii (1980) no Brasil, trabalhando com metribu zin em misturas com trifluralin em condições de campo, verifica ram que não houve nenhum efeito significativo para peso de 100 sementes, peso de planta, produção de grãos e para sintomas de fitotoxidade.

\subsection{Profundidade de incorporação de vernolate no solo e SEUS EFEITOS NA PLANTA}

COLE et alii (1964) verificaram que vernolate e trifluralin foram mais eficientes no controle de gramíneas, quando incorporados ao solo, e que vernolate causou mais injū rias : na soja.

JOHNSON (1971) na Geörgia, E.U.A., trabalhando com vernolate injetado ao solo, à profundidade de 5 a $8 \mathrm{~cm}$ e vernolate incorporado ao solo através de gradagens a profundi dades de $5 \mathrm{~cm}$, verificou que não houve diferenças no rendimen to da soja, sendo que o controle das plantas daninhas foi melhor quando vernolate foi injetado no solo.

Vernolate a $3,0 \mathrm{~kg}$ i.a./ha incorporado ao solo não mostrou nenhum efeito prejudicial às plantas de soja, segundo GRASSI et alii (1972). 
A incorporação de vernolate a profundidades de 10 a $15 \mathrm{~cm}$ com grade de discos, tem resultado em um controle mais eficiente das plantas daninhas, e que aparentemente vernolate é absorvido e metabolizado pela soja. Ocasionalmente , pode provocar injürias, mas os sintomas desaparecem em poucas semanas, contudo, representa um potencial de redução no rendi mento, segundo WAX (1973).

MASSARIOL e LAM-SANCHEZ (1974) em São Paulo, BR, trabalhando com vernolate a $3,03 \mathrm{~kg}$ i.a.ha e trifluralin a $0,86 \mathrm{~kg}$ i.a./ha aplicados em pré-plantio incorporados, verificaram que não houve efeitos prejudiciais destes herbicidas na nodulação, floração, altura de plantas, inserção da I. vagem e maturação da cultivar Viçoja.

COVOLO e WATT (1974) no Rio Grande do Sul, BR, utili zaram dentre outros os herbicidas vernolate a $3,0 \mathrm{~kg}$ i.a.ha e trifluralin a $0,86 \mathrm{~kg}$ i.a.ha, incorporados, não verificaram qualquer efeito fitotóxico a cultivar santa Rosa em um solo com 2\% de matéria orgânica.

VENTURELLA et alii (1976) no Rio Grande do Sul, BR, utilizaram vernolate a $4,2 \mathrm{~kg}$ i.a./ha em incorporação rasa (2 cm), verificaram injūrias nas plantas da cultivar Pérola, na fase inicial, mas sem influência na produção final de grãos. Vernolate foi o melhor tratamento no controle das dicotiledôneas presentes, assim como proporcionaram um controle de 90 a $100 \%$ de Digitaria sanguinalis.

LORENZI e DAVIS (1976) no Paraná, BR, 
visando controlar as principais plantas daninhas que infestam as lavouras do Paraná, testaram 14 herbicidas recomendados ou com características promissoras para a cultura da soja e ape nas o tratamento vernolate causou severa injūria nas plantas, diminuindo o peso da matéria seca das plantas, refletindo negativamente na produção.

\subsection{Profundidade de incorporação de PEndimethalin No SOlO E SEUS EFEITOS NA PLANTA}

STRUCKMEYER et alii (1976) em Wisconsin, E.U.A., em estudos anatômicos sobre o efeito de pendimethalin e trifluralin sobre a estrutura celular da soja, observaram que as injūrias causadas pelos herbicidas foram a expansão dos vasos xilemáticos, hipertrofia das células, anelamento do tecido vascular na região cortical e desorganização das células. LEIDERMAN e GRASSI (1974) em São Paulo, BR, utilizando pendimethalin a $0,50,0,75$ e $1,0 \mathrm{~kg}$ i.a./ha, incorpo rados ao solo, verificaram que não houve prejuízo ao normal desenvolvimento e produção das cultivares de soja Santa Rosa e IAC-2 .

De acordo com BAKER (1976) para se obter uma máxima eficiência com mínimas injūrias na soja, pendimethalin deve ser incorporado de 2,5 a $7,5 \mathrm{~cm}$ de profundidade, no máxi mo 6 horas após à aplicação.

DEUBER (1976) en São Paulo, BR, trabalhando com 
pendimethalin em pré-emergência para se conhecer a tolerância de diversas culturas e a eficiência no controle de diferentes espécies de plantas daninhas, verificou que pendimethalin nas doses de 0,50 e $0,82 \mathrm{~kg}$ i.a./ha em misturas com linuron a 0,50 e 0,75 kg i.a./ha ou metribuzin a 0,24 e 0,40 kg i.a./ha, mostrou-se perfeitamente tolerante a cultivar Santa Rosa, e hou ve um excelente controle das principais plantas daninhas presentes.

BUENDIA (1978) em Minas Gerais, BR, trabalhando com pendimethalin em diferentes formulações nas doses de 0,96 a $1,99 \mathrm{~kg}$ i.a./ha, incorporados ao solo, com 1,2\% de maté ria orgânica, concluiu que a população da cultivar UFV-l não foi prejudicada, e que não houve efeito fitotóxico para a soja, não havendo diferenças na produção, altura de planta, peso de 100 sementes e qualidade de sementes. A formulação 500 EN, nas doses de 1,0 e $1,30 \mathrm{~kg}$ i.a./ha reduziu a altura de inserção da là vagem.

COVOLO et alii (1978) no Rio Grande do Sul, BR, concluiu que pendimethalin em solo de várzea não afetou a produção e não foi verificado nenhum sintoma visual de fitotoxidade à soja. Entretanto COVOIO et alii (1978), no Rio Grandedo Sul, BR, uti lizando misturas de pendimethalin a $1,0 \mathrm{~kg}$ i.a.ha e metribu zin a 0,28 kg i.a./ha, em pré-plantio incorporado em um solo Podzólico Vermelho-Amarelo com 13\% de argila e 2\% de matéria orgânica, verificou um retardamento no crescimento inicial da cultivar Santa Rosa, além de reduzir a população, mas não 
houve reflexos na produção.

Como pode ser visto, a literatura é relativa mente abundante em registros que abordam a utilização, em soja, dos herbicidas trifluralin, metribuzin, vernolate e pendi methalin, seus efeitos no desenvolvimento e rendimento da cultura, a importância da profundidade de incorporação desses herbicidas, bem como em citações relativas a maior ou menor sele tividade que determinadas cultivares apresentam em relação aos princípios ativos arrolados.

A maioria dos autores aceitam que os herbicidas, citados, afetam o desenvolvimento e produção dasoja, mas estes efeitos estão sempre na dependência das doses, tolerância das cultivares e profundidade de incorporação dos herbici das. Algumas discordâncias entre os autores é verificado, o que denota que em alguns pontos o assunto não está perfeita mente esclarecido, sendo que novos trabalhos devem ser realizados com o intuito de contribuir para a completa elucida ção deste tema. 


\section{MATERIAL E MÉTODOS}

A presente pesquisa foi conduzida na Unidade de Execução de Pesquisa de Âmbito Estadual (UEPAE - EMBRAPA), no município de Dourados, MS, localizado na latitude 22014's, longitude 54049' $\mathrm{W}$ e altitude de 452 metros, em um Latossolo Roxo Distrófico, textura argilosa, de média fertilidade, rele vo plano e cujas características químicas e físicas encontram-se na Tabela 1 .

Foram conduzidos dois experimentos, sendo um em condições de campo e outro em casa-de-vegetação.

\subsection{EXPER IMENTO DE CAMPO}

No experimento em condições de campo, o deli neamento estatístico utilizado foi o de blocos casualizados, com parcelas subdivididas, conforme esquema apresentado na Ta 


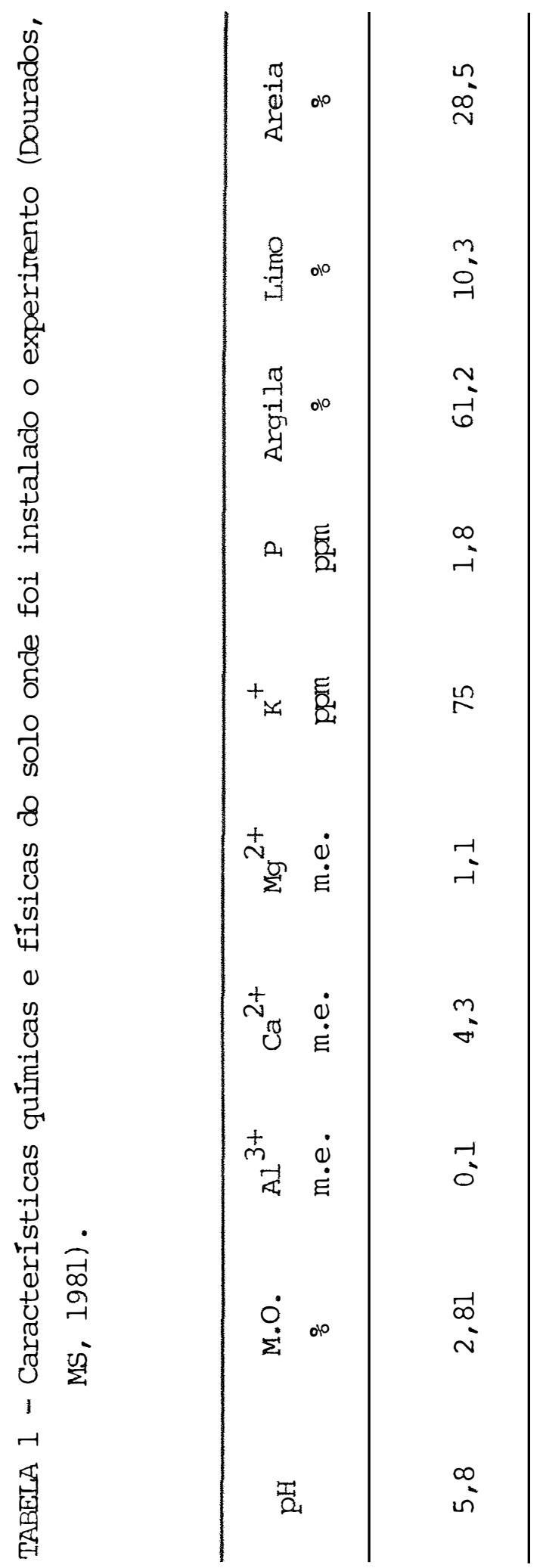


bela 2, sendo que as parcelas foram os herbicidas e as testemunhas; e as subparcelas as profundidades de incorporação.

TABETA 2 - Esquena das análises de variância, dos dados obtidos, nas determinações do experimento de campo.

Causas de variação

Graus de liberdade

Tratamentos $(\mathrm{T})$ 5

Blocos 2

Resíduo (a) 10

(Parcelas)

Profundidade de incorporação (P) 3

Interação TxP 15

Resíduo (b) 36

Subparcelas 71

A ārea total de cada subparcela foi de $15 \mathrm{~m}^{2}$ $(3,0 \times 5,0 \mathrm{~m})$, e ārea útil de colheita de $8 \mathrm{~m}^{2}(2,0 \mathrm{x} 4,0 \mathrm{~m})$ ou seja, as quatro linhas centrais, desprezando-se $50 \mathrm{~cm}$ nas extremidades.

Foi utilizado a cultivar de soja Paraná e os herbicidas usados foram trifluralin $(\alpha, \alpha, \alpha$, trifluoro-2,6-dinitro-N,N-dipropil-p-toluidina), metribuzin (4-amino-6-tert -butil-3-(metiltio)-1,2,4-triazina-5-(4 H)-one, vernolate (S propil-dipropil-tiocarbamato), e pendimethalin (N-(l-etil-pro 
pil)-3,4-dimetil-2,6-dinitrobenzenamina), nas doses respectivas de 2,$5 ; 0,75 ; 5,0$ e $3,0 \ell /$ ha, do produto comercial, ou 1,$11 ; 0,36 ; 3,86$ e $1,50 \mathrm{~kg}$ do i.a.Ma, incorporado ao solo às profundidades de $0 ; 2,5 ; 5,0$ e $10,0 \mathrm{~cm}$, no perfil do solo.

A área do ensaio recebeu uma adubação antes do plantio, em área total, sendo distribuído a lanço o correspon dente a $200 \mathrm{~kg} / \mathrm{ha}$, da fórmula 0-30-10, incorporado ao solo através de duas gradagens, e as sementes foram inoculadas por ocasião do plantio com Rhizobium japonicum numa proporção de $200 \mathrm{~g}$ do produto comercial por $50 \mathrm{~kg}$ de sementes.

Os herbicidas foram aplicados em área total das subparcelas, com pulverizador à pressão constante $\left(\mathrm{CO}_{2}\right)$, equipados com bicos Teejet 80.02 , em leque, e com pressão de $2,10 \mathrm{~kg} / \mathrm{cm}^{2}$, com um consumo de calda de $300 \ell /$ ha. Os herbicidas foram aplicados no dia 18/12/80, das 16 às 18 horas, quan do a temperatura média do ar era de $26,70^{\circ}$, a umidade relativa em torno de 67\%, o céu apresentava-se nublado, e o solo se co com poucos torrões. A primeira precipitação ocorreu no dia seguinte após a aplicação $(34,0 \mathrm{~mm})$, como pode ser observado pelos dados em apêndice.

A incorporação dos herbicidas no perfil do so10, às profundidades de 5,0 e $10,0 \mathrm{~cm}$ foram realizadas com en xada rotativa, tracionada por microtrator Agrale e a incorporação à profundidade de $2,5 \mathrm{~cm}$, foi feita manualmente, atravēs de rastelos.

Além dos tratamentos com herbicidas haviam par 
celas testemunhas, sendo uma capinada e outra sem capina, sofrendo estas parcelas os mesmos processos de revolvimento do solo, apesar de não estar presente nenhum produto químico.

A soja foi semeada manualmente em sulcos dé $3 \mathrm{~cm}$ de profundidade, procurando-se distribuir cerca de 30 se mentes por metro linear, sendo as linhas espaçadas de $50 \mathrm{~cm}$.

Para efeito de comparação dos tratamentos foram medidos os seguintes parâmetros: população inicial da ărea útil de colheita aos 3 dias apōs a emergência, população final por ocasião da colheita, altura (cm) de plantas aos 15, 30 e 60 dias à emergência e, na colheita, altura (cm) de inserção da primeira vagem, peso (g) da matéria seca das plantas daninhas em $1 \mathrm{~m}^{2}$ do centro de cada subparcela aos 20 dias após emergência, número de vag.ens por planta, número de ramificações por planta, peso (g) de grãos por planta e peso (kg) total de grãos por subparcela.

As alturas de plantas e de inserção da primeira vagem, número de vagens por planta, número de ramificações por planta e peso de grãos por planta foram realizado por amostragens de 10 plantas nas quatro linhas centrais de cada subparcela.

Para comparação de médias, adotou-se o teste de Tukey ao nível de 5\% de probabilidade. 


\subsection{EXPERIMENTO EM CASA-DE-VEGETAÇÃO}

No experimento em casa-de-vegetação foram utilizadas as cultivares de soja Paranā, Bossier e Santa Rosa, se meadas em vasos plāsticos de 9,0 litros de capacidade.

Os herbicidas usados foram trifluralin, metribuzin, vernolate e pendimethalin, nas doses respectivas de 2,$5 ; 0,75 ; 5,0$ e 3,0 /ha do produto comercial, ou 1,1; 0,36; $3,86 \mathrm{e} 1,5 \mathrm{~kg}$ i.a./ha, sendo incorporados ao solo às profundi dades de $0 ; 2,5 ; 5,0$ e $10,0 \mathrm{~cm}$.

Para garantir que somente essas faixas seriam tratadas, foram utilizados pedaços de plásticos, que eram colocados nas profundidades desejadas e em seguida, colocava-se terra peneirada até completar o volume do vaso, que por sua vez era pulverizado com o herbicida, com o mesmo tipo de pulverizador, pressão e bicos utilizados no experimento de cam po, ou seja, pulverizador à pressão constante $\left(\mathrm{CO}_{2}\right)$, com bicos Teejet $80.02 \mathrm{em}$ leque, e pressão de $2,10 \mathrm{~kg} / \mathrm{cm}^{2}$, com um consumo de calda equivalente a $300 \mathrm{l} / \mathrm{ha}$.

Após a aplicação, o pedaço de plástico, juntamente com a respectiva porção de terra era retirada do vaso e homogeneizada, retornando o volume de terra ao vaso, onde as sementes eram semeadas à uma profundidade de $3 \mathrm{~cm}$. Utilizou se de 5 sementes, procurando-se, após a emergência, deixar apenas uma plântula por vaso.

Para que não houvesse percolação dos herbicidas para as camadas mais profundas, logo após a semeadura, os 
vasos eram colocados em bandejas com água, e por estes possuí rem três orifícios no seu fundo, a água subia por capilaridade e desta maneira era oferecida às sementes e às plântulas, durante o decorrer do experimento.

A terra utilizada nos vasos foi coletada numa área próxima a do ensaio de campo, sendo que esta área recebeu uma adubação de $200 \mathrm{~kg} / \mathrm{ha}$ da fórmula 0-30-10, incorporado ao solo através de duas gradagens.

As sementes de soja, tal como no experimento de campo, foram inoculadas por ocasião do plantio com Rhizobium japonicum, na proporção de $200 \mathrm{~g}$ do produto comercial por 50 $\mathrm{kg}$ de sementes.

A casa-de-vegetação foi mantida durante todo o transcorrer do experimento com temperaturas oscilando entre 28 e $32^{\circ} \mathrm{C}$.

Foram incluídos no experimento, vasos-testemunhas, ou seja, sem presença de nenhum herbicida, sendo que es tes recipientes também recebiam os mesmos processos de homoge neização das respectivas camadas do perfil do solo, a que os outros tratamentos estariam sujeitos.

Para efeito de comparação dos tratamentos, foram avaliados os seguintes parâmetros: altura (cm) das plantas aos 7 e 15 dias após emergência; peso (g) da matéria seca da parte aérea e radicular aos 15 dias após emergência.

o peso da matéria seca da parte aérea e radicu 
lar foi conseguida utilizando estufa de circulação de ar forÇada com temperatura $65^{\circ} \mathrm{C}$ até peso constante.

A separação das raízes e terra foram conseguidas através do peneiramento dentro d'água do volume de terra do vaso . O delineamento estatístico utilizado foi intei ramente casualizado em parcelas sub-subdivididas, conforme o esquema apresentado na Tabela 3, sendo que as parcelas foram os herbicidas e a testemunha; as subparcelas as cultivares cul tivares e as sub-subparcelas as profundidades de incorporação. As análises foram realizadas com auxílio de computador eletrônico IBM 1130, do Departamento de Matemática e Estatística da ESALQ.

TABELA 3 - Esquema das análises de variância, dos dados obtidos, nas determinações efetuadas em casa-de-vegetação.

Causas de variação

Tratamentos (T)

Resíduos (a)

(Parcelas)

Cultivares (C)

Interação TxC

Resíduo (b)

(Subparcelas)

Profundidade de incorporação (P)

Interação TxP

Interação CxP

Interação TxCXP

Resíduo (c)
Graus de liberdade

4

10

(14)

2

8

20

Sub-subparcelas

44

3

12

6

24

90 


\section{RESULTADOS E DISCUSSÃO}

\subsection{EXPERIMENTO DE CAMPO}

Analisando-se os possíveis efeitos dos trata mentos e subtratamentos na produção de grãos e seus componentes (Tabela 4), observa-se que a testemunha sem capina apresentou resultados inferiores aos demais tratamentos, para todos os parâmetros, exceto na que diz respeito ao peso de 100 grãos que se mostrou estatisticamente igual. E evidente que esta redução na produção da testemunha sem capina foi devido à concorrência das plantas daninhas pelos elementos essenciais à sobrevivência e reprodução das espécies, confirmando resultados de KNAKE e SLIFE (1965) e MOOLANI et alii (1964), onde. a concocrêencia das plantas daninhas causou redução na produção da soja em 27 e 55, respectivamente. 
Os tratamentos envolvendo herbicidas, não dife riram significativamente da testemunha capinada, em nenhum ca so. Esses resultados estão em acordo com os obtidos por LOREN ZI (1976), VENTURELA et alii (1976), BUENDIA (1978) e BRAZ et alii (1980), que constataram, respectivamente, a não inter ferência do metribuzin, vernolate, pendimethalin e triflura lin, nos componentes de rendimentos da soja.

Com relação aos subtratamentos, não se constatou diferenças estatísticas entre as profundidades de incorpo ração dos herbicidas, para qualquer um dos parâmetros medidos.

Na Tabela 5 são apresentadas as médias da altụ ra de plantas aos 15, 30 e 60 dias após a emergência, e na co lheita, além da altura de inserção da primeira vagem.

Observa-se que a altura de planta aos 15 dias, foi estatisticamente igual para todos os tratamentos; por outro lado, as avaliações da altura nas três seguintes épocas , e da inserção da primeira vagem, mostraram que a testemunha sem capina apresentou valores estatisticamente superiores. O ocorrido pode ser explicado pela competição por luz, entre sô ja e as plantas daninhas, o que provocou um aumento na altura da soja. Segundo HINSON e HANSON (1962); JOHNSON e HARRIS (1967); HICKS et alii (1969); REMUSSI et alii (1971); DOSS e THURLOW (1974) e BUENO et alii (1975), conforme se aumenta a população, aumenta-se a altura das plantas de soja.

Reforça também esta hipótese, o fato de que, aos 15 dias após a emergência da soja não havia ainda se esta 
belecido a competição, e a altura das plantas da testemunha sem capina, não apresentou diferenças dos outros tratamentos. No que diz respeito aos subtratamentos (profun didades de incorporação dos herbicidas), não se verificou diferenças estatísticas significativas entre os mesmos.

Pelos dados constantes da Tabela 6, pode-se ve rificar que nenhum dos herbicidas utilizados afetou a população inicial e final, concordando com resultados obtidos por LORENZI (1976), com metribuzin; BUENDIA (1978), com pendime thalin; NEGI e FUNDERBURK (1967), com trifluralin e GRASSI et alii (1972), com vernolate.

A população final e número de ramificações por planta, observados na testemunha sem capina, foram estatisticamente inferiores aos demais tratamentos. O descréscimo na população final, foi atribuído à morte de plantas de soja, em função da competição que sofreram por parte das plantas dani nhas, pelo melhor aproveitamento dos elementos essenciais necessārios à manutenção das espécies; quanto ao número de rami ficações, verifica-se que a testemunha sem capina, sofrendo $\underline{u}$ ma maior competição por luz apresentou um desenvolvimento da soja com maior ênfase no sentido vertical em detrimento da emissão de ramificações laterais. Este fato pode ser comparado ao plantio da soja em altas populações, o que segundo REMUSSI et alii (1971) diminui o nümero de ramificações das plantas. No que diz respeito ao peso da matéria séca das plantas daninhas, verifica-se tambēm na Tabela 6 que o trata- 
mento metribuzin foi o que propiciou menor valor, sendo estatisticamente diferente de pendimethalin e da testemunha sem capina, mas semelhante a trifluralin e vernolate; a testemunha sem capina foi a que apresentou maior peso, diferindo estatisticamente dos demais tratamentos, ficando evidenciado que os herbicidas apresentaram controle sobre a infestação de plantas daninhas, que era composta de aproximadamente: 70\% de Cassia tora, 20\% de Brachiaria plantaginea e $10 \%$ de Amaranthus hybridus, onde metribuzin apresentou o melhor controle, propiciando o menor pe so da matéria seca de plantas daninhas.

Quanto às profundidades de incorporação dos herbicidas, não se verificou nenhum efeito significativo sobre as avaliações levadas a efeito.

As duas ünicas interações significativas entre tratamentos e profundidades de incorporação, foram para população inicial e final.

A interação entre tratamentos e profundidades de incorporação sobre a população inicial é apresentada na Tâ bela 7, onde observa-se que pendimethalin incorporado a $5 \mathrm{~cm}$ apresentou resultados estatisticamente superior a 0 e $10 \mathrm{~cm}$, não diferindo, entretanto, da profundidade de incorporação de $2,5 \mathrm{~cm}$.

Pendimethalin aplicado na superfície e incorpo rado a $10 \mathrm{~cm}$ reduziu significativamente a população. Este resultado vem de certo modo, confirmar a recomendação de BAKER (1976), que preconiza que pendimethalin deve ser incorporado 
de 2,5 a $7,5 \mathrm{~cm}$ para se obter uma máxima eficiência sem provo car danos na soja.

Para os demais tratamentos, a população inicial não foi significativamente afetada pela profundidade de incor poração.

Quanto aos efeitos da interação entre tratamen tos e profundidades de incorporação de herbicidas sobre a população final da soja (Tabela 8), constatou-se que trifluralin incorporado a $2,5 \mathrm{~cm}$ de profundidade, propiciou um número de plantas significativamente superior ao obtido quando se posicionou a 5,0 cm no perfil do solo; contudo aplicado à super fície ou incorporado a $10 \mathrm{~cm}$ de profundidade, o mesmo herbici da não mostrou diferenças significativas na população final da cultura. Acredita-se que a incorporação a $5 \mathrm{~cm}$ tenha colocado a semente no início da germinação em contato com uma maior concentração do herbicida, pois segundo OLIVER e FRANS (1968), à medida que se aumenta a concentração do herbicida próximo à zona do sistema radicular no início da germinação, maiores são as possibilidades de interferência com as plantas de soja.

Pendimethalin incorporado a 5,0 e $2,5 \mathrm{~cm}$ de pro fundidade, propiciaram populações de plantas estatisticamente superiores às obtidas pelo mesmo herbicida, quando este foi a plicado à superfície ou incorporado a $10 \mathrm{~cm}$. Os demais tratamentos não apresentaram diferenças decorrentes da profundidade de incorporação (Tabela 8). Observando-se os dados de precipitação após a aplicação dos herbicidas (Apêndice), verifi- 
ca-se que ocorreu uma chuva de $34,0 \mathrm{~mm}$ no dia seguinte à aplí cação. Isso pode ter contribuído para uma melhor distribuição dos herbicidas mais solúveis, ou seja, metribuzin e vernola te, e conseqüentemente somente os herbicidas trifluraline pen dimethalin devem ter permanecido em maior concentração nas zo nas em que foram colocados. Daí então a interferência desses herbicidas na população de plantas de soja. 


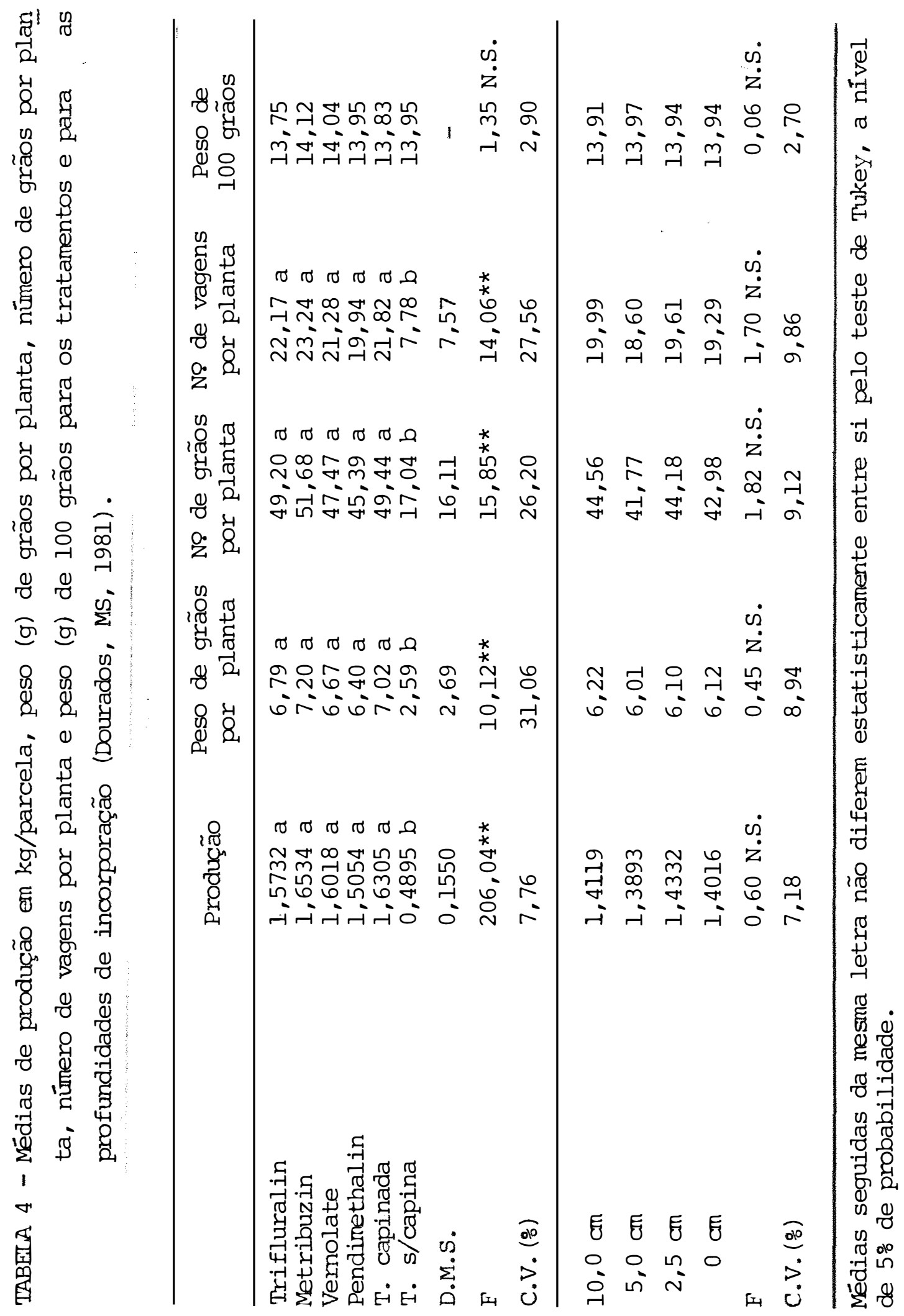




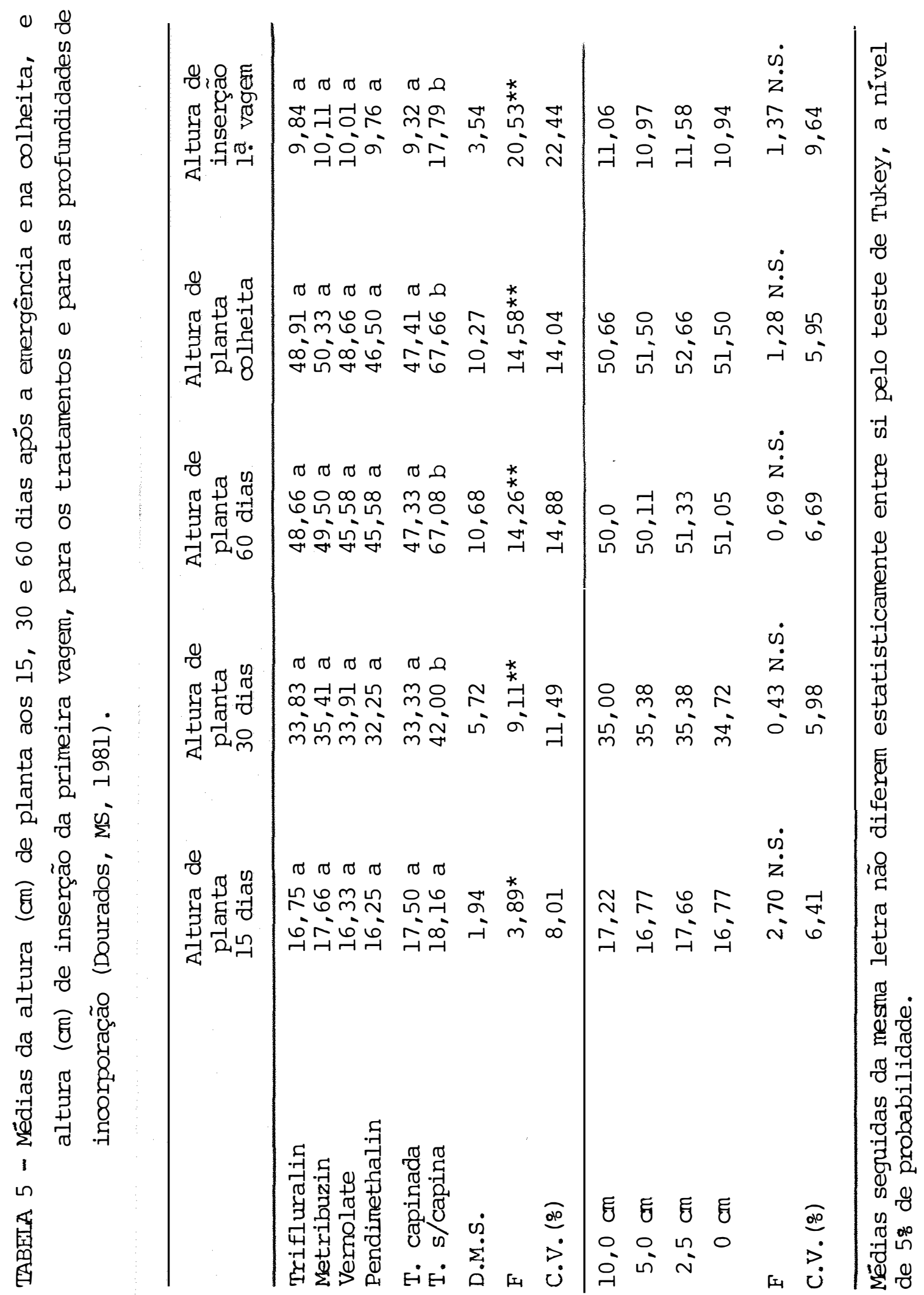




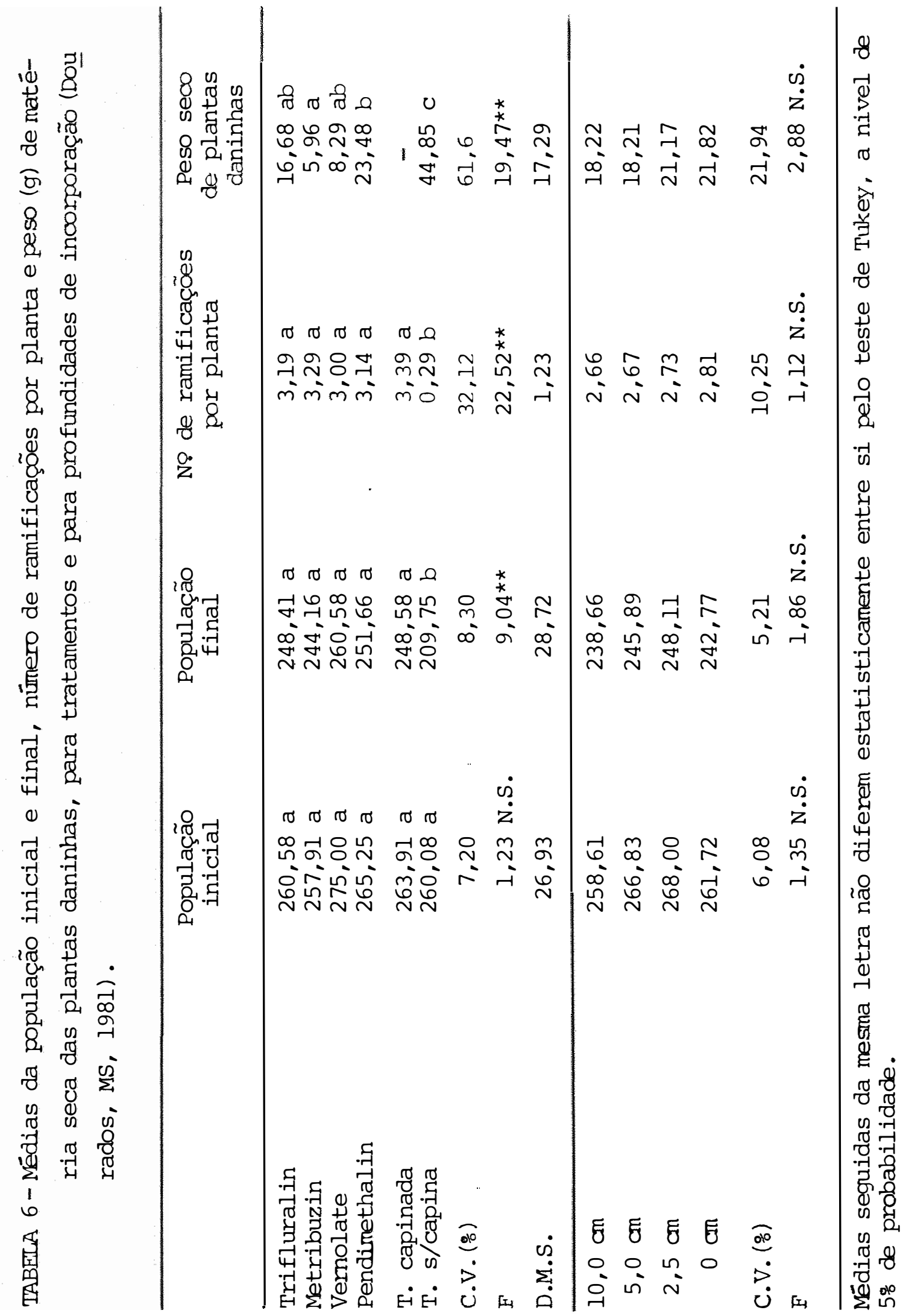


TABELA 7 - Médias das interações entre tratamentos e profundidades de incorporação sobre a população inicial de plantas de soja - núme ro de plantas en $8 \mathrm{~m}^{2}$ (Dourados, MS, 1981).

\begin{tabular}{lllll}
\hline & $0 \mathrm{~cm}$ & $2,5 \mathrm{~cm}$ & $5,0 \mathrm{~cm}$ & $10,0 \mathrm{~cm}$ \\
\hline Trifluralin & 260,0 & 272,6 & 242,0 & 267,6 \\
Metribuzin & 268,6 & 255,6 & 245,0 & 262,3 \\
Vernolate & 278,6 & 276,0 & 282,0 & 263,3 \\
Pendinethalin & $2,37,0 \mathrm{~b}$ & $285,0 \mathrm{ab}$ & $287,6 \mathrm{a}$ & $251,3 \mathrm{~b}$ \\
T. capinada & 263,3 & 268,6 & 275,0 & 248,6 \\
T. s/capina & 262,6 & 250,0 & 269,3 & 258,3 \\
D.M.S. 35,66 & & & & \\
F & & & & \\
C.V. (\%) $\quad 6,08$ & & & & \\
\hline
\end{tabular}

Médias seguidas da mesma letra e médias não acrmpanhadas de letras, compa radas na horizontal não diferem estatisticamente entre si pelo teste de Tukey, a nivel de 5\% de probabilidade 
TABFilA 8 - Médias das interações entre tratamentos e profundidades de incorporação sobre a população final de plantas de soja - número de plantas em $8 \mathrm{~m}^{2}$ (Dourados, MS, 1981).

\begin{tabular}{|c|c|c|c|c|}
\hline & $0 \mathrm{~cm}$ & $2,5 \mathrm{~cm}$ & $5,0 \mathrm{~cm}$ & $10,0 \mathrm{~cm}$ \\
\hline Trifluralin & $248,0 a b$ & 261,3 a & $231,3 \mathrm{~b}$ & $253,0 a b$ \\
\hline Metribuzin & 251,3 & 243,0 & 234,3 & 248,0 \\
\hline Vernolate & 261,3 & 261,6 & 267,3 & 252,0 \\
\hline Pendimethalin & $227,0 \mathrm{~b}$ & $270,3 a$ & $270,6 a$ & $238,6 \mathrm{~b}$ \\
\hline T. capinada & 249,6 & 252,3 & 256,0 & 236,3 \\
\hline T. s/capina & 219,3 & 200,0 & 215,6 & 204,0 \\
\hline D.M.S. & & & & \\
\hline $\mathrm{F}$ & & & & \\
\hline C.V. (\%) & & & & \\
\hline
\end{tabular}

Médias seguidas da mesma letra e médias não acompanhadas de letras, compa radas na horizontal não diferem estatisticamente entre si pelo teste de Tukey, a nivel de 5\% de probabilidade. 


\subsection{EXPERIMENTO EM CASA-DE-VEgETAÇÃO}

Na Tabela 9 estão apresentadas as médias da al tura de plantas aos 7 e 15 dias após a emergência, e o peso da ma téria seca da parte aérea eradicular aos 15 dias após a emergência da soja, para os tratamentos estudados. Observa-se que para altura de planta aos 7 dias a testemunha foi superior aos demais tratamentos e que pendimethalin e metribuzin não diferiram entre si, mas foram superiores estatisticamente a trifluralin e vernolate.

Para altura de plantas aos 15 dias, a testemunha continuou sendo superior aos demais tratamentos, sendo que pendimethalin foi estatisticamente superior ao metribuzin, que por sua vez, foi superior ao trifluralin e vernolate.

Ficou evidenciado pelas alturas de plantas medidas, nestas duas épocas que nas condições em que foi conduzido o experimento, os herbicidas estudados interferiram nega tivamente no desenvolvimento da soja, sendo que o mesmo não foi verificado em condições de campo. Um dos fatores envolvidos é que os solos dos vasos foram mantidos com umidade à capacidade de campo, o que segundo ANDERSON (1977), favorece o aumento da concentração das moléculas do herbicida na solução do solo, pois a maior quantidade de āgua facilita a liberação das moléculas de herbicida, dos pontos de adsorção; havendo com isso uma maior absorção dessas moléculas pelas raízes, o que provocaria uma redução no crescimento. 
Para o peso da matéria seca da parte aérea, vernolate foi significativamente inferior a todos os tratamentos, que não a presentaram diferenças entre si. Estes resultados estão de acordo com os obtidos por LORENZI e DAVIS (1976), que dos 14 her bicidas recomendados para soja, apenas vernolate causou problemas de injūrias, reduzindo o peso das plantas e produção.

Quanto ao peso do sistema radicular, triflura lin foi o que apresentou maior valor, sendo estatisticamente superior aos demais, inclusive à testemunha, que não diferiu do metribuzin, mas sendo superior a pendimethalin e vernolate, que propiciaram o menor peso.

Salienta-se o resultado obtido por trifluralin uma vez que DEPETRIS (1976) e STANDIFER e TOMAS (1965), verificaram uma inibição das raízes laterais, onde a raiz primária estavam em contato com a zona tratada por trifluralin. En tretanto, OLIVER e FRANS (1968) verificaram redução nas raízes laterais, mas por outro lado, se a inibição não é suficien te para causar morte da plântula, então pode haver um efeito compensativo, onde a planta produziria maior número de raízes laterais, quando deixasse a zona tratada pelo trifluralin. KUST e STRUCKMEYER (1971) acrescenta que trifluralin reduziu o crescimento da parte aérea, mas não prejudicou o crescimento das raízes.

A interação entre tratamentos e cultivares sobre a altura de plantas aos 7 dias é apresentado na Tabela 10, 
onde se observa que para as cultivares Paraná e Bossier , os tratamentos trifluralin e vernolate afetaram significativa mente a altura das plantas. Quanto a cultivar Santa Rosa, todos os tratamentos foram estatisticamente diferentes, apresen tando-se em ordem decrescente de altura à testemunha, pendime thalin, metribuzin, trifluralin e vernolate.

Da análise desses resultados, pode-se verificar que a cultivar santa Rosa, foi a que mostrou maior sensibilidade aos herbicidas usados, sendo afetada por todos eles; ao passo que as cultivares Paraná e Bossier, somente foram afetadas na sua.altura de plantas aos 7 dias, apenas, pelos herbicidas trifluralin e vernolate.

Esta diferença na sensibilidade e na resposta das cultivares aos herbicidas é citada por HARDCASTLE et alii (1974), WAX et alii (1976) e ROGERS (1974).

Na Tabela 11 é apresentada a interação entre tratamentos e profundidades de incorporação sobre a média da altura de plantas aos 7 dias após a emergência, onde verifi ca-se que a interação foi significativa somente para pendimethalin e vernolate. Pendimethalin incorporado a $10 \mathrm{~cm}$, apresentou-se superior às médias de alturas obtidas com a incorpo ração a $5 \mathrm{~cm}$ e em aplicação em superfície, entretanto, não dí feriu da profundidade de $2,5 \mathrm{~cm}$.

Quanto ao tratamento vernolate, a incorporação de $10 \mathrm{~cm}$ foi que propiciou a menor altura, sendo diferente das demais, que não apresentaram variações eśtatísticas entre si. 
O resultado obtido para vernolate apresenta-se de certa forma discordante com MASSARIOL e LAM-SANCHEZ (1974), que trabaIhando com vernolate incorporado à profundidade em torno de 5 a $10 \mathrm{~cm}$, observaram não ter havido influência deste produto na altura de planta.

Analisando-se a interação entre tratamentos e cultivares sobre a média de alturade plantas, aos 15 dias após a emergência da soja, apresentada na Tabela 12, observa se que os herbicidas tiveram um efeito negativo no desenvolvi mento das plantas, diminuindo a altura das três cultivares, a presentando as testemunhas com valores estatisticamente superiores aos demais tratamentos.

Quanto a cultivar Bossier, o tratamento trifluralin foi o que propiciou menor valor. Os tratamentos pendimethalin e metribuzin apresentaram valores intermediários. De um modo geral, pode-se afirmar que numa escala crescente de efeitos negativos, quanto ao desenvolvimento das três cultiva res, situa-se pendimethalin, metribuzin, vernolate e triflura lin.

Estes efeitos negativos no desenvolvimento das plantas, diminuindo suas alturas confirmam resultados obtidos por NEGI e FUNDERBURK (1967), para trifluralin e HARDCASTLE et alii (1974) para metribuzin, onde afirmam que estes herbicidas inibem o crescimento da soja.

Pela análise estatística dos dados constantes na Tabela 13, verifica-se que a interação entre tratamentos e 
profundidades de incorporação sobre a média da altura de plantas aos 15 dias após a emergência da soja, foi significativa, sendo que os herbicidas metribuzin e vernolate, quando incorporados a profundidades de $10 \mathrm{~cm}$, provocaram um decréscimo na altura de planta, apresentando valores significativamente inferiores. Quanto aos outros herbicidas não foi verificado diferenças significativas quanto à profundidade de incorporação.

A não interferência da profundidade de incorpo ração de trifluralin sobre a altura das plantas, é discordante dos resultados obtidos por KUST e STRUCKMEYER (1971) e DAVIS et alii (1976), que observaram efeitos significativos da profundidade de incorporação sobre a altura das plantas de soja.

Quanto ao resultado obtido por metribuzin, de certa forma, estão em perfeito acordo com os obtidos por McCUTCHEN et alii (1975) e WAX (1977), que afirmam que metribuzin provoca mais injürias na soja quando incorporado, do que em aplicação em superfície.

A interação entre tratamentos e cultivares sobre a média do peso da matēria seca de raĩzes aos 15 dias após a emergên cia da soja é apresentada na Tabela 14, onde verifica-se que a interação foi altamente significativa, com os herbicidas afetando o peso radicular das cultivares.

Para a cultivar Paraná, trifluralin apresentou o maior valor para peso da matéria seca de raízes, sendo estatistica mente superior a vernolate e pendimethalin, mas não diferindo 
da testemunha e do metribuzin. Vernolate não diferiu do pendi methalin, metribuzin e da testemunha.

Para a cultivar Bossier, trifluralin foi tạ bém o que apresentou maior valor, sendo significativamente sụ perior aos demais tratamentos, inclusive à testemunha, que não diferiram entre si.

Quanto a cultivar Santa Rosa, trifluralinvol tou a apresentar valores estatisticamente superior aos demais. Vernolate foi o tratamento que apresentou menor peso de raízes, mas não sendo significativamente diferente de pendimetha lin, que por sua vez, não diferiu da testemunha.

Metribuzin foi superior a vernolate e pendimethalin.

Os valores de peso da matéria seca de raízes, o.btidos por trifluralin, principalmente para as cultivares Bossier e San ta Rosa, parece ser contraditório à afirmação de STANDIFER e TOMAS (1965), DEPETRIS (1976) e PAULA (1972), que trifluralin inibe o crescimento lateral das raízes. Contudo, pode ser explicado uma vez que houve a inibição com aparecimento de raízes curtas e engrossadas nas faixas em que entrava em contato com o produto; sendo que logo após a raiz principal atravessar as faixas tratadas, havia um efeito compensatório com maior nū mero de emissões de raízes laterais, o que resultou num maior peso do sistema radicular, confirmando resultados de OLIVER e FRANS (1968) .

Na Tabela 15 são apresentadas as médias da 
interação entre tratamentos e profundidades de incorporação, sobre o peso da matéria seca de raízes 15 dias após a energência dạ soja, onde se observa que quando trifluralin foi incorporado a $10 \mathrm{~cm}$, apresentou valores estatisticamente inferior às demais profundidades. Este resultado confirma os obtidos por DEPETRIS (1976), que estudando as profundidades de incorporação de trí fluralin, verificou que a incorporação a $10 \mathrm{~cm}$ resultou numa redução no peso das raízes no 14 @ dia após a semeadura.

Quanto ao herbicida metribuzin, conforme se au mentou a profundidade de incorporação, diminuiu-se o peso da matéria seca das raízes, o mesmo ocorrendo para vernolate. Estes resultados são concordantes de certo modo, à a firmação de MeCuTCHEN (1975) para metribuzin, de que a incorporação aumenta o grau de injūria para a soja. Entretanto, é discordante dos resulta dos obtidos por CRAWFORD e ROGERS (1975), que verificaram que o comportamento do metribuzin foi o mesmo, tanto em pré-emer gência ou incorporado, e que nenhuma das doses utilizadas apresentou problemas à soja.

A interação entre tratamentos e cultivares sobre o peso da matéria seca da parte aérea da soja 15 dias após emergência, é apresentada na Tabela 16, onde verifica-se que para a cultivar Paraná, o herbicida trifluralin apresentou valores superiores a vernolate e não diferindo dos demais tratamentos. De certa forma, este resultado está de acordo com a afirmação de COLE et alii (1974), de que nas mesmas condições vernolate causa mais injūrias à soja que trifluralin. 
Para a cultivar Bossier, a testemunha foi su perior aos demais tratamentos que não apresentaram diferenças entre si videnciando uma sensibilidade de certo modo unifor me dessa cultivar aos herbicidas usados, quanto ao parâmetro medido.

No referente a cultivar Santa Rosa, vernolate apresentou valores estatisticamente inferior aos outros tratamentos que não diferiram entre si, podendo-se observar que a cultivar Santa Rosa mostrou-se sensivel somente ao herbicida vernolate, sendo tolerante aos demais herbicidas, quanto ao peso da matéria seca da parte aérea.

Pela análise dos dados constantes da Tabela 17 pode-se verificar que a interação entre tratamentos e profundidades de incorporação dos herbicidas sobre a média de peso da matéria seca da parte aérea da soja 15 dias após a emergência, foi al tamente significativa, observando-se que pendimethalin quando incorporado a $10 \mathrm{~cm}$, apresentou valores significativamente su perior do que quando aplicado em superfície do solo, que por sua vez não diferiu das profundidades de 2,5 e 5,0 cm.

Quanto a trifluralin, metribuzin e vernolate, conforme aumenta-se a profundidade de incorporação, diminui se o peso da matéria seca da parte aérea, sendo que a aplicação en supe $\underline{r}$ fície foi estatisticamente superior à incorporação a $10 \mathrm{~cm}$. E $\underline{\mathbf{s}}$ tes resultados estão de certo modo, de acordo com os obtidos por KUST e STRUCKMEYER (1971) para trifluralin, onde verifica ram que a incorporação de trifluralin a $10 \mathrm{~cm}$ reduziu o crescimento da parte aérea. 


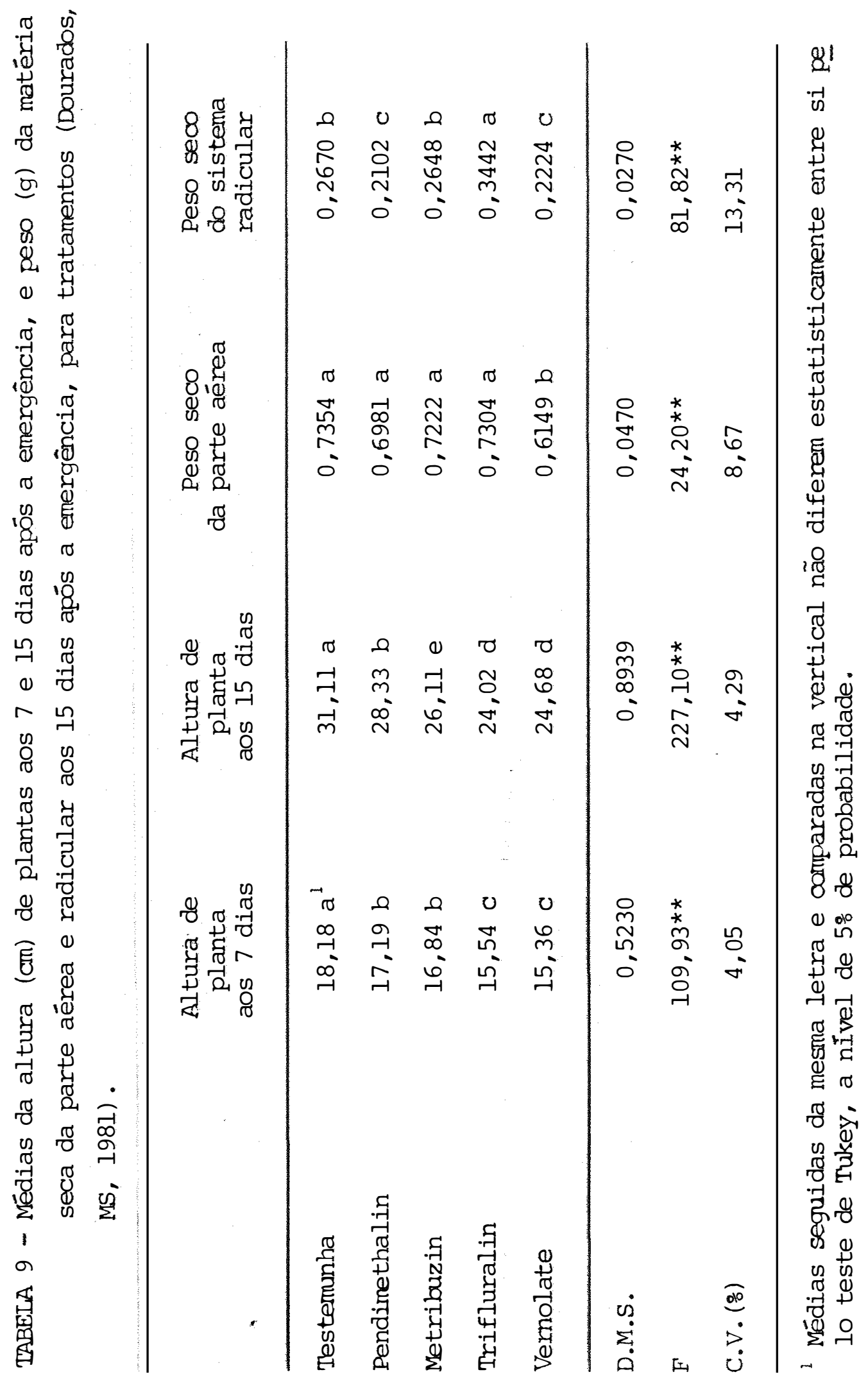


TABEIA 10 - Interação entre tratamentos e cultivares sobre a média de altura (cm) de planta de soja aos 7 dias após emergência (Doura dos, MS, 1981).

\begin{tabular}{lccc}
\hline & 'Paraná' & 'Bossier' & 'Santa Rosa \\
\hline Testemunha & $18,20 \mathrm{a}$ & $16,33 \mathrm{a}$ & $20,00 \mathrm{a}$ \\
Pendimethalin & $17,50 \mathrm{a}$ & $15,70 \mathrm{a}$ & $18,37 \mathrm{~b}$ \\
Metribuzin & $17,50 \mathrm{a}$ & $15,83 \mathrm{a}$ & $17,20 \mathrm{c}$ \\
Trifluralin & $16,08 \mathrm{~b}$ & $14,37 \mathrm{~b}$ & $16,16 \mathrm{~d}$ \\
Vemolate & $16,37 \mathrm{~b}$ & $14,33 \mathrm{~b}$ & $15,37 \mathrm{e}$ \\
\hline & & & \\
D.M.S. & & & \\
F & & & \\
C.V. (\%) & & & \\
\hline
\end{tabular}

Médias seguidas da mesma letra, comparadas na vertical não diferem esta tisticamente entre si pelo teste de Tukey, a nível de 5\% de probabilidā de. 
TABELA 11 - Interação entre tratamentos e profundidades de incorporação , sobre a média da altura (cm) de planta aos 7 dias após a emergência da soja (Dourados, MS, 1981).

\begin{tabular}{|c|c|c|c|c|c|}
\hline & & $0 \mathrm{~cm}$ & $2,5 \mathrm{~cm}$ & $5,0 \mathrm{~cm}$ & $10,0 \mathrm{~cm}$ \\
\hline \multicolumn{2}{|l|}{ Testermunha } & $18,27 \mathrm{a}$ & 18,16 a & $18,38 \mathrm{a}$ & $17,88 \mathrm{a}$ \\
\hline \multicolumn{2}{|l|}{ Pendimethalin } & $16,88 \mathrm{~b}$ & $17,05 \mathrm{ab}$ & $16,77 \mathrm{~b}$ & $18,05 \mathrm{a}$ \\
\hline \multicolumn{2}{|l|}{ Metribuzin } & 16,94 a & $16,66 \mathrm{a}$ & $16,61 \mathrm{a}$ & 17,16 a \\
\hline \multicolumn{2}{|l|}{ Trifluralin } & $15,72 \mathrm{a}$ & $15,38 \mathrm{a}$ & $15,22 \mathrm{a}$ & $15,83 \mathrm{a}$ \\
\hline \multicolumn{2}{|l|}{ Vermolate } & $16,33 \mathrm{a}$ & $16,00 \mathrm{a}$ & $15,33 \mathrm{a}$ & $13,77 \mathrm{~b}$ \\
\hline D.M.S. & 1,0813 & & & & \\
\hline$F$ & $5,00 * *$ & & & & \\
\hline$C . V .(\%)$ & 5,25 & & & & \\
\hline
\end{tabular}

Médias seguidas da mesma letra, comparadas na horizontal não diferem es tatisticamente entre si pelo teste de Tukey, a nível de 5\% de probabili dade. 
TABEJAA 12 - Interação entre tratamentos e cultivares, sobre a média de al tura (cm) das plantas aos 15 dias após a emergência da soja (Dourados, MS, 1981).

\begin{tabular}{|c|c|c|c|c|}
\hline & & 'Paranā' & 'Bossier' & 'Santa Rosa' \\
\hline Testernunha & & $30,33 a$ & 30,62 a & 32,27 a \\
\hline Pendimethalin & & $27,95 \mathrm{~b}$ & $26,87 \mathrm{~b}$ & $30,16 \mathrm{~b}$ \\
\hline Metribuzin & & $27,00 \mathrm{~b}$ & $26,00 \mathrm{c}$ & $26,33 \mathrm{c}$ \\
\hline Vemolate & & $24,70 \mathrm{c}$ & $25,12 \mathrm{c}$ & $24,20 \mathrm{~d}$ \\
\hline Trifluralin & & $24,16 \mathrm{c}$ & $22,66 \mathrm{~d}$ & $25,25 \mathrm{~d}$ \\
\hline D.M.S. & 1,088 & & & \\
\hline$F$ & $14,07 * *$ & & & \\
\hline C.V. (응) & 3,32 & & & \\
\hline
\end{tabular}

Médias seguidas da mesma letra, comparadas na vertical não diferem esta tisticamente entre si pelo teste de Tukey, a nivel de 5\% de probabilidā de. 
TABEIA 13 - Interação entre tratamentos e profundidades de incorporação , sobre a média da altura (crn) de plantas aos 15 dias após a emergência da soja (Dourados, MS, 1981).

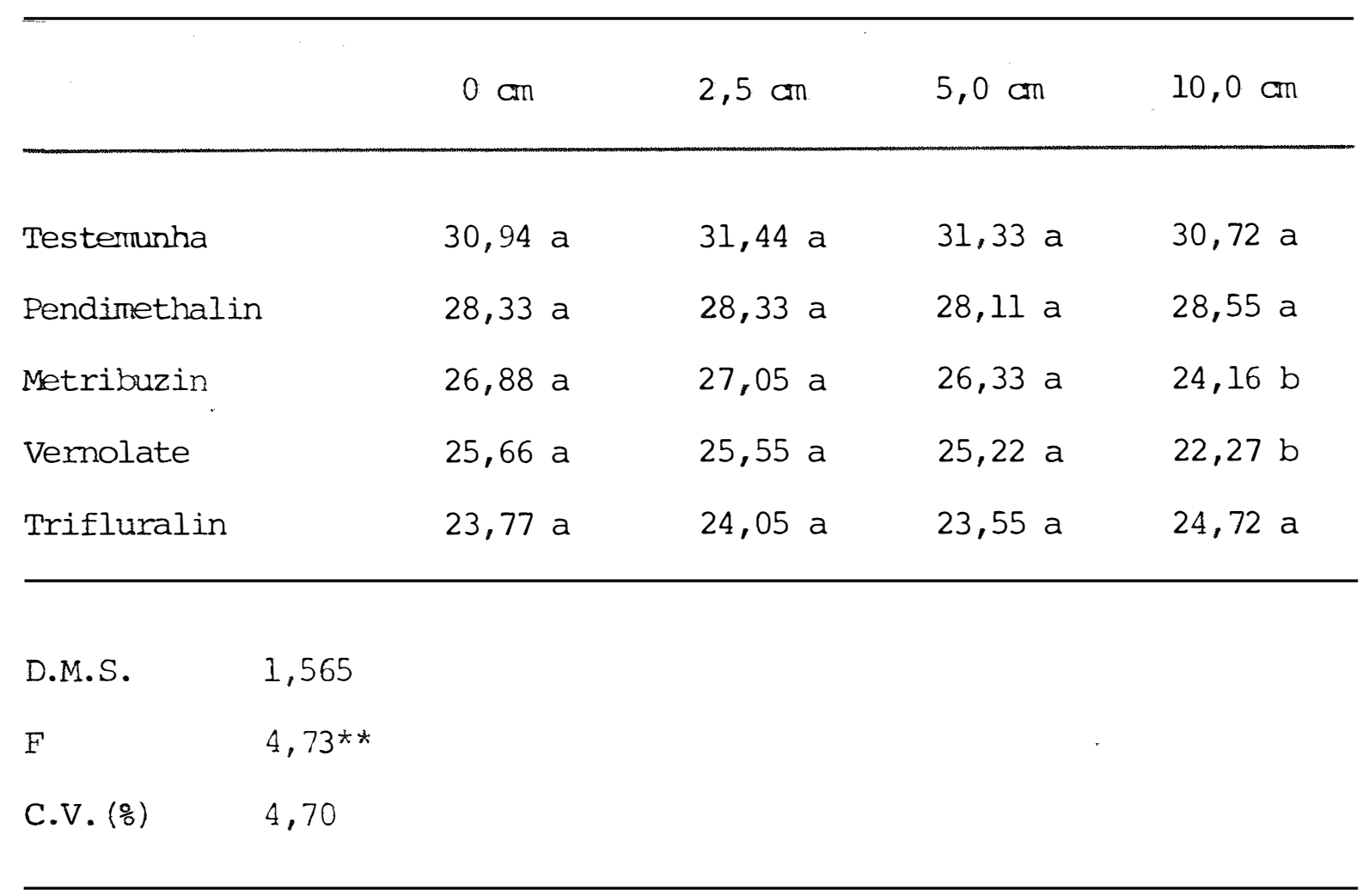

Médias seguidas da mesma letra, comparadas na horizontal não diferem es tatisticamente entre si pelo teste de Tukey, a nível de 5\% de probabili dade. 
TABEIA 14 - Interação entre tratamentos e cultivares sobre a média de peso (g) da matéria seca das raízes aos 15 dias após a emergência da soja (Dourados, MS, 1981).

\begin{tabular}{|c|c|c|c|c|}
\hline & & 'Paranā' & 'Bossier' & 'Santa Rosa' \\
\hline Trifluralin & & $0,3546 a$ & $0,3093 a$ & 0,3688 a \\
\hline Testemunha & & $0,3265 \mathrm{ab}$ & $0,2296 \mathrm{~b}$ & $0,2449 \mathrm{bcc}$ \\
\hline Metribuzin & & $0,3124 \mathrm{ab}$ & $0,2174 \mathrm{~b}$ & $0,2646 \mathrm{~b}$ \\
\hline Vernolate & & $0,2742 \mathrm{bcc}$ & $0,2309 \mathrm{~b}$ & $0,1622 \mathrm{~d}$ \\
\hline Pendimethalin & & $0,2533 \mathrm{c}$ & $0,1741 \mathrm{~b}$ & $0,2023 \mathrm{~cd}$ \\
\hline D.M.S. & 0,0586 & & & \\
\hline$F$ & $4,72 * \star$ & & & \\
\hline$C \cdot V \cdot\left(\frac{\circ}{\circ}\right)$ & 18,33 & & - & \\
\hline
\end{tabular}

Médias seguidas da mesma letra, comparadas na vertical não diferem esta tisticamente pelo teste de Tukey, a nivel de 5\% de probabilidade. 
TABELA 15 - Interação entre tratamentos e profundidades de incorporação, sobre a média de peso ( $g$ ) da matéria seca de raízes aos 15 dias após a emergência da soja (Dourados, MS, 1981).

\begin{tabular}{|c|c|c|c|c|c|}
\hline & & $0 \mathrm{~cm}$ & $2,5 \mathrm{~cm}$ & $5,0 \mathrm{~cm}$ & $10,0 \mathrm{~cm}$ \\
\hline Testemunha & & $0,2834 a$ & $0,2558 \mathrm{a}$ & $0,2673 a$ & $0,2615 a$ \\
\hline Pendimethalin & & $0,2041 \mathrm{a}$ & 0,1982 a & 0,2188 a & $0,2198 \mathrm{a}$ \\
\hline Trifluralin & & 0,3641 a & $0,3508 \mathrm{a}$ & 0,3731 a & $0,2889 \mathrm{~b}$ \\
\hline Metribuzin & & $0,3319 a$ & $0,2815 \mathrm{ab}$ & $0,2442 \mathrm{bc}$ & $0,2015 \mathrm{c}$ \\
\hline Vernolate & & 0,3115 a & $0,2298 \mathrm{~b}$ & $0,2003 \mathrm{bc}$ & $0,1481 \mathrm{c}$ \\
\hline D.M.S. & 0,0527 & & & & \\
\hline $\mathrm{F}$ & $5,88 * \star$ & & & & \\
\hline C.V. (\%) & 16,27 & & & & \\
\hline
\end{tabular}

Médias seguidas da mestra letra, comparadas na horizontal não diferem en tre si pelo teste de Tukey, a nível de 5\% de probabilidade. 
TABEIA 16 - Interação entre tratamentos e cultivares, sobre a média do pe so (g) da matéria seca da parte aérea da soja aos 15 dias após emergência (Dourados, MS, 1981).

\begin{tabular}{|c|c|c|c|c|}
\hline & & 'Paranā' & 'Bossier' & 'Santa Rosa' \\
\hline Trifluralin & & $0,7971 \mathrm{a}$ & $0,6262 \mathrm{~b}$ & $0,7688 \mathrm{a}$ \\
\hline Metribuzin & & $0,7666 \mathrm{ab}$ & $0,6358 \mathrm{~b}$ & 0,7641 a \\
\hline Pendimethalin & & $0,7564 \mathrm{ab}$ & $0,6260 \mathrm{~b}$ & $0,7120 \mathrm{a}$ \\
\hline Testermunha & & $0,7470 \mathrm{ab}$ & $0,7241 \mathrm{a}$ & $0,7349 a$ \\
\hline Vernolate & & $0,6945 \mathrm{~b}$ & $0,6329 \mathrm{~b}$ & $0,5174 \mathrm{~b}$ \\
\hline D.M.S. & 0,048 & & & \\
\hline $\mathrm{F}$ & $10,56 * *$ & & & \\
\hline C.V. (음) & 8,67 & & & \\
\hline
\end{tabular}

Médias seguidas da mesma letra, comparadas na vertical não diferem entre si pelo teste de Tukey, a nível de 5\% de probabilidade. 
TABEIA 17 - Interação entre tratamentos e profundidades de incorporação, sobre a média de peso ( $g$ ) da matéria seca da parte aérea da soja aos 15 dias apōs a emergência (Dourados, MS, 1981).

\begin{tabular}{|c|c|c|c|c|c|}
\hline & & $0 \mathrm{~cm}$ & $2,5 \mathrm{~cm}$ & $5,0 \mathrm{~cm}$ & $10,0 \mathrm{~cm}$ \\
\hline \multicolumn{2}{|l|}{ Testemunha } & $0,7558 a$ & $0,7213 a$ & $0,7438 a$ & $0,7205 a$ \\
\hline \multicolumn{2}{|l|}{ Pendimethalin } & $0,6531 \mathrm{~b}$ & $0,6679 \mathrm{ab}$ & $0,7235 \mathrm{ab}$ & 0,7481 a \\
\hline \multicolumn{2}{|l|}{ Trifluralin } & $0,7688 a$ & $0,7401 \mathrm{ab}$ & $0,7388 \mathrm{ab}$ & $0,6751 \mathrm{~b}$ \\
\hline \multicolumn{2}{|l|}{ Metribuzin } & 0,7825 a & $0,7644 a$ & $0,6874 \mathrm{bc}$ & $0,6544 \mathrm{c}$ \\
\hline \multicolumn{2}{|l|}{ Vemolate } & $0,7466 a$ & $0,6349 \mathrm{~b}$ & $0,5761 \mathrm{bc}$ & $0,5022 c$ \\
\hline D.M.S. & 0,0838 & & & & \\
\hline $\mathrm{E}$ & $6,21 * *$ & & & . & \\
\hline C.V. (으) & 9,66 & & & & \\
\hline
\end{tabular}

Médias seguidas da mesma letra, cormparadas na horizontal não diferem es tatisticamente entre si pelo teste de Tukey, a nível de 5\% de probabili dade. 


\section{CONCLUSÕES}

A anālise e interpretação dos resultados, nas condições em que a pesquisa foi conduzida, permitiu-se concluir que:

a) Em condições de campo, a profundidade de incorporação e os herbicidas utilizados não afetaram o desennvolvimento e produção da soja.

b) O controle das plantas daninhas, expresso pelo peso da matéria seca no 20 a dia após a emergência da soja, não foi influenciado pela profundidade de incorporação dos herbici das. 
c) Em condições de vasos em casa-de-vegetação, os herbicidas e as profundidades de incorporação afetaram a altura e o peso seco da parte aérea e radicular das plantas de soja.

d) A altura das plantas foi mais afetada pelos herbicidas tri fluralin e vernolate, principalmente pelo vernolate, quando incorporado a $10 \mathrm{~cm}$ de profundidade. Também o pendime thalin quando aplicado à superfície, afetou a altura das plantas.

e) $O$ peso seco da parte aērea sofreu maior interferência do vernolate, quando incorporado a $10 \mathrm{~cm}$, o mesmo ocorrendo com trifluralin e metribuzin. Pendimethalin afetou mais quan do aplicado à superfície.

f) o peso do sistema radicular sofreu uma maior interferência pelo pendimethalin e vernolate. Trifluralin, metribuzin e vernolate afetaram com maior intensidade quando incorporados na profundidade de $10 \mathrm{~cm}$. 


\section{LITERATURA CITADA}

ANDERSON, W.P., 1980. Weeds Science Principles. New York, ed. West Publishing Company, 598p.

BAKER, R.S., 1976. Weeds in agronomic crops. Research Report North Carolina Agricultural Experiment Station, Raleigh, $29: 1$.

BRASII. Fundação Instituto Brasileiro de Geografia e Estatística, 1979. Anuário estatístico do Brasil. Rio de Janeiro, v.40, p.321.

BRAZ, B.A.; A.N. CHEHATA; A.P. PARDINHO e D.A.S. MARCONDES, 1980. Estudo comparativo de diversas misturas de herbicidas na cultura da soja. In: XIII Seminārio Brasileiro de Herbicidas e Ervas Daninhas, Ilhéus/Itabuna, p.64. |Resumos 
BUENDIA, J.P.L., 1978. Estudo de formulações de Pendimethalin nas culturas de algodão (Gossypium hirsutum L.), milho (Zea mays L.) e soja |Glycine $\max$ (L.) Merrill| no Triângulo Mineiro. In: XII Seminário Brasileiro de Herbicidas e Ervas Daninhas, Fortaleza, p.46-47. |Resumos|

BUENO, L.C.S.; C.S. SEDIYAMA e C. VIEIRA, 1975. Efeitos de espaçamento, densidade e época de plantio sobre duas variedades de soja. Experientiae, Viçosa, 20: 263-287.

COBLE, H.D. e J.W. SCHRADER, 1973. Soybean tolerance to metribuzin. Weed Science, Urbana, Ill., 2l (4): 308-309.

COLE, R.H.; R.S. BOYCE e E.L. WISK, 1964. Performance of several soybean herbicides. Soybean Digest, Hudson, Iowa, 24(6): 17.

COVOLO, L. e M.R. WATT, 1974. Primeiro ensaio de competição de herbicidas na cultura de soja na região de Santa Maria. In: X Seminário Brasileiro de Herbicidas e Ervas Daninhas, Santa Maria, p.60-61.

COVOLO, L.; T. DARIVA; J.O.C. JOBIM e S.L.O. MACHADO, 1978. Competição de herbicidas na cultura da soja em várzea orizícola. Lavoura Arrozeira, Porto Alegre, (305): 41-48.

COVOLO, L.; T. DARIVA e S.L.O. MACHADO, 1978. Controle químico das plantas daninhas na cultura da soja |Glycine max (L.) Merrill|. In: XII Seminário Brasileiro de Herbicidas e Ervas Daninhas, Fortaleza, p.105. |Resumos| 
CRAWFORD, S.H. e R.L. ROGERS, 1975. Metribuzin combination with preplant incorporated herbicides. In: Proceedings 28th Annual Meeting. Southern Weed Science Society, Mermpis, Tenn., p. 73 .

DAVIS, I.B.; J.A. COLLIER; T.H. GARNER e B.K. WEBB, 1976. Herbicide incorporation studies cotton and soybeans. In: Proceedings Beltwide Cotton Production Research Conference, p.119-121.

DEPETRIS, J.A., 1976. Efectos de concentración y profundidad de incorporaciōn de la trifluralina sobre plántulas de soya. Información Tecnica Instituto Nacional de Tecnología Agropecuaria, Córdoba, 71: 5 .

DEUBER, R., 1976. Utilização de penoxalin em misturas com outros herbicidas de pré-emergência. In: XI Seminário Brasileiro de Herbicidas e Ervas Daninhas, Londrina, p.9-10.

DOSS, B.D. e D.L. THURLOW, 1974. Irrigation row and plant population in relation to growth characteristics of two soybean varieties. Agronomy Journal, Madison, Wisc., 66:

ESPINOSA, W.G.; R.S. ADAMS e R. BEHEREMS, 1968. Interation effects of atrazine and C.D.A.A., linuron, amibin or trifluralin on soybean growth. Agronomy Journal, Madison, Wis., $60(2): 183-185$.

GRASSI, N.; L. LEIDERMAN e S.G.P. SILVEIRA, 1972. Novo herbicida de pré-plantio incorporado para a cultura da soja. In: IX Seminário Brasileiro de Herbicidas e Ervas Daninhas, Campinas, p.7. | Resumos | 
HARDCASTLE, W.S.; R.E. WILKINSON e C.T. YOUNG, 1974. Metribuzin effects on seed constituents of soybean varieties. Weed Science, Urbana, Ill., 22(6): 575-577.

HARGRODER, T.G. e R.L. ROGERS, 1974. Behavior and fate of metribuzin in soybean and tremp sisbania. Weed Science, Urbana, Ill., 22(3): 238-245.

HICKS, R.D. e D.H. FLETCHALL, 1964. Preplant incorporation studies in cotton and soybean weed control. In: Proceedins 17th Annual Meetint. Southern Weed Science Society, Jackson, Miss., p.157.

HICKS, D.R.; J.W. PENDLETON; R.L. BERNARD e T.L. JOHNSTON, 1969. Response of soybean plant tipes to planting patterns. Agronomy Journal, Madison, Wis., 61: 290-293.

HINSON, K. e W.D. HANSON, 1962. Competition studies in soybean. Crop Science, Madison, Wis., 2 $: 117-123$.

HONDA, T.; D. MENEGHEL e P.R. MACHADO, 1976. Controle de ervas daninhas de folhas largas na cultura da soja. In: XI Seminário Brasileiro de Herbicidas e Ervas Daninhas, Londrina, p.80-81. |Resumos |

JOHNSON, B.J. e HARRIS, H.B., 1967. Influence of plant population on the yield and other characteristics of soybeans. Agronomy Journal, Madison, Wis., 59: 447-449.

JOHNSON, B.J., 1971. Response of weeds and soybeans to vemolate and other herbicides. Weed Science, Urbana, Ill., 19(4): 
KNAKE, E.L. e F.W. SLIFE, 1965. Giant fatail seeded at various times in corn and soybeans. Weeds, Urbana, Ill., 13(4):

KNAKE, E.L.; A.P. APPLEBY e W.R. FURTICK, 1967. Soils incorporation and site of uptake of preemergence herbicides. Weeds, Urbana, Ill., 15(3): 228-232.

KUST, C.A. e B.E. STRUCKMEYER, 1971. Effects of trifluralin on growth, nodulation and anatomy of soybean. Weed Science, Urbana, Ill., 19: 147-152.

LEIDERMAN, L. e N. GRASSI, 1974. Dois novos herbicidas de préplantio incorporado para a cultura da soja. In: X Seminário Brasileiro de Herbicidas e Ervas Daninhas, Santa Maria, p.28. | Resumos $\mid$

LORENZI, H.J., 1976. Determinação dos limites de dosagens de metribuzin para duas diferentes variedades de soja. In: XI Seminário Brasileiro de Herbicidas e Ervas Daninhas, Londrina, p.76. |Resumos|

LORENZI, H.J. e G.G. DAVIS, 1976. Competição de herbicidas na cultura da soja. In: XI Seminário Brasileiro de Herbicidas e Ervas Daninhas, Londrina, p.67. |Resumos|

MASSARIOL, A.A. e A. LAM-SANCHEZ, 1974. Efeito de cinco herbicidas na nodulação, controle de ervas daninhas esprodução da cultura da soja |Glycine max (L.) Merrill|. Científica, Jaboticabal, $\underline{1}(1): 18-23$. 
MCCUTCHEN, T.; J.R. OVERTON; T.H. MORGAN E L.S. JEFFERY, 1975. Tank mixtures of metribuzin and various dinitroanilines herbicides for soybean weed control. In: Proceedings 28th Annual Meeting. Southern Weed Science Society, Memphis, Tenn., p. 74 .

MOOLANI, M.R.; E.L. KNAKE e F.W. SLIFE, 1964. Competition of smooty pig weed with corn and soybeans. Weeds, Urbana, Ill., $12(2): 126-128$.

NEGI, N.S. e H.H. FUNDERBURK, 1967. Response of several plant species to trifluralin and benefin. Proceedings 20 th Southern weed Conference, 369. Apud: Weed Abstract, 18(3): 164-165. (citação 1031)

OLIVER, R. e R.E. FRANS, 1968. Inhibition of cotton and soybean roots from incorporated trifluralin and persistence in soil. Weed Science, Urbana, Ill., 16(2): 199-203.

PARKER, C., 1966. The importance of shoot entry in action of herbicides applied to soil. Weeds, Urbana, Ill., 14: 117-121.

PAULA, J.F., 1972. Trabalhos sobre efeitos de herbicidas na cultura da soja. Viçosa, Universidade Federal de Viçosa, $8 \mathrm{p}$.

REMUSSI, C.; H. SAUMELL e H. GUTIERREZ, 1971. Influencia de Ia densidad de siembra en soya el rendimiento y sus componentes. Rev. de la Fac. de Agronomía y Veterinaría de Buenos Aires, 19 : 99-107.

STANDIFER, L.C. e C.H. TOMAS, 1965. Response of johnsongrass to soil incorporated trifluralin. Weeds, Urbana, Ill., 13: $302-306$. 
STRUCKMEYER, B.E.; L.K. BINING e R.G. HARVEY, 1976. Effect of dinitroaniline herbicides in a soil medium on snap bean and soybeans. Weed Science, Urbana, Ill., 24 (4): 366-369.

VELloso, J.A.R.O. e N.G. FLECK, 1980. Comportamento de cultivares de soja |Glycine max (L.) Merrill| em resposta a diferentes épocas de aplicação do metribuzin. Planta Daninha, Campinas, $3(1): 35-40$.

VENTURELLA, L.R.C.; O. RUCKHEIM FILHO e G.G. DAVIS, 1976. Herbicidas isolados no controle às ervas daninhas da soja. In: XI Seminário Brasileiro de Herbicidas e Ervas Daninhas, Londrina, p.71. |Resumos|

WAX, L.M., 1973. Weed control. In: CALDWELL, B.E., ed. Soybeans: improvements, production and uses. Madison, Wis., American Society of Agronomy, p.417-457. (Agronomy, 16)

WAX, L.M.; E.W. STOLLER e R.L. BERNARD, 1976. Diferencial response of soybean cultivars to metribuzin. Agronomy Journal, Madison, Wis., 68: 484-486.

WAX, L.M., 1977. Incorporation depth and rainfall on weed control in soybeans with metribuzin. Agronomy Jaurnal, Madison, Wis., 69: 107-109. 
60.

7. APÊNDICE 
TABELA 18 - Dados meteorológioos diários do mês de dezembro de 1980.

\begin{tabular}{|c|c|c|c|c|c|c|c|}
\hline DIAS & $\mathrm{TM}$ & $\mathrm{Tm}$ & $\mathrm{T}$ & UR & $\mathrm{Ne}$ & $\mathrm{P}$ & In \\
\hline 01 & 31,4 & 19,1 & 24,6 & 58 & 8 & 0,0 & 7,5 \\
\hline 02 & 32,3 & 18,8 & 23,1 & 72 & 7 & 0,0 & 8,6 \\
\hline 03 & 25,6 & 16,9 & 21,6 & 84 & 5 & 22,0 & 7,8 \\
\hline 04 & 31,5 & 18,9 & 24,9 & 71 & 4 & 14,1 & 11,1 \\
\hline 05 & 33,8 & 19,3 & 25,5 & 63 & 2 & 0,0 & 12,0 \\
\hline 06 & 34,8 & 19,1 & 25,7 & 53 & 3 & 0,0 & 11,0 \\
\hline 07 & 34,8 & 17,6 & 26,2 & 54 & 1 & 0,0 & 12,5 \\
\hline 08 & 34,9 & 19,1 & 26,8 & 55 & 1 & 0,0 & 11,9 \\
\hline 09 & 35,4 & 21,3 & 28,6 & 54 & 3 & 0,0 & 10,3 \\
\hline 10 & 35,0 & 20,5 & 27,3 & 65 & 7 & 0,0 & 10,4 \\
\hline 11 & 31,2 & 21,9 & 25,8 & 70 & 7 & 0,0 & 1,0 \\
\hline 12 & 30,1 & 20,5 & 23,9 & 82 & 6 & 22,2 & 3,4 \\
\hline 13 & 33,3 & 21,1 & 26,7 & 65 & 1 & 0,1 & 12,1 \\
\hline 14 & 33,9 & 21,7 & 27,2 & 58 & 2 & 0,0 & 12,1 \\
\hline 15 & 33,5 & 18,7 & 25,8 & 49 & 0 & 0,0 & 12,6 \\
\hline 16 & 35,0 & 17,7 & 27,0 & 50 & 1 & 0,0 & 12,5 \\
\hline 17 & 35,5 & 17,9 & 27,3 & 51 & 1 & 0,0 & 12,5 \\
\hline 18 & 34,0 & 18,0 & 26,7 & 67 & 7 & 0,0 & 9,5 \\
\hline 19 & 26,8 & 20,7 & 23,0 & 94 & 10 & 34,0 & 0,4 \\
\hline 20 & 25,7 & 21,9 & 23,2 & 95 & 10 & 5,5 & 0,0 \\
\hline 21 & 23,9 & 19,3 & 21,3 & 90 & 10 & 65,2 & 0,0 \\
\hline 22 & 25,8 & 19,8 & 22,2 & 95 & 10 & 0,3 & 0,3 \\
\hline 23 & 27,7 & 20,9 & 22,9 & 86 & 6 & 10,8 & 5,1 \\
\hline 24 & 29,3 & 18,9 & 24,0 & 77 & 2 & 0,4 & 10,0 \\
\hline 25 & 30,7 & 19,2 & 24,7 & 78 & 7 & 0,0 & 7,7 \\
\hline 26 & 30,0 & 21,7 & 23,8 & 79 & 9 & 1,0 & 4,3 \\
\hline 27 & 29,1 & 21,2 & 23,5 & 91 & 7 & 5,5 & 2,1 \\
\hline 28 & 33,3 & 21,7 & 26,7 & 76 & 5 & 15,4 & 9,0 \\
\hline 29 & 34,3 & 21,9 & 27,6 & 70 & 4 & 0,0 & 11,3 \\
\hline 30 & 35,3 & 22,3 & 26,6 & 74 & 5 & 0,0 & 8,2 \\
\hline 31 & 34,5 & 22,2 & 25,9 & 74 & 6 & 0,2 & 9,3 \\
\hline Total & & & & & & 196,7 & 246,5 \\
\hline Média & 31,7 & 20,0 & 24,8 & 74 & 5,1 & & \\
\hline
\end{tabular}

TM = temperatura média das mäximas absolutas $\left({ }^{\circ} \mathrm{C}\right)$

$T_{m}=$ temperatura média das minimas absolutas $\left({ }^{\circ}\right)$

$\mathrm{T}=$ temperatura média $\left(\sigma_{\mathrm{C}}\right)$

$\mathrm{UR}=$ umidade relativa $(\%)$

$\mathrm{Ne}=$ nebulosidade (escala 0 - 10)

$\mathrm{P}=$ precipitação (mm)

In = insolação (horas e décimos) 
62.

TABEIA 19 - Dados meteorológicos diārios do mês de janeiro de 1981.

\begin{tabular}{|c|c|c|c|c|c|c|c|}
\hline DIAS & TM & $\operatorname{Tr}$ & $\mathrm{T}$ & UR & $\mathrm{Ne}$ & $\mathrm{P}$ & In \\
\hline 01 & 33,0 & 21,7 & 25,0 & 82 & 7 & 29,6 & 6,5 \\
\hline 02 & 32,2 & 20,5 & 26,4 & 69 & 6 & 4,4 & 10,6 \\
\hline 03 & 33,9 & 20,1 & 26,9 & 63 & 6 & 0,0 & 10,0 \\
\hline 04 & 30,5 & 22,3 & 25,3 & 80 & 8 & 0,1 & 3,0 \\
\hline 05 & 30,9 & 22,3 & 25,3 & 79 & 7 & 10,7 & 7,0 \\
\hline 06 & 33,2 & 22,4 & 26,9 & 69 & 5 & 0,0 & 10,6 \\
\hline 07 & 33,0 & 23,1 & 26,1 & 83 & 9 & 0,0 & 5,1 \\
\hline 08 & 31,1 & 22,0 & 24,3 & 94 & 10 & 0,5 & 1,1 \\
\hline 09 & 28,6 & 20,9 & 23,3 & 90 & 7 & 37,5 & 1,5 \\
\hline 10 & 31,7 & 19,7 & 25,2 & 79 & 6 & 4,6 & 6,7 \\
\hline 11 & 27,4 & 20,9 & 22,7 & 94 & 9 & 31,5 & 1,6 \\
\hline 12 & 28,2 & 21,1 & 24,6 & 84 & 8 & 39,8 & 1,5 \\
\hline 13 & 29,1 & 21,2 & 24,5 & 93 & 8 & 2,4 & 3,6 \\
\hline 14 & 31,9 & 20,3 & 25,4 & 76 & 4 & 6,0 & 11,7 \\
\hline 15 & 32,7 & 20,5 & 26,7 & 70 & 6 & 0,0 & 11,7 \\
\hline 16 & 32,3 & 22,9 & 26,8 & 74 & 6 & 0,0 & 10,6 \\
\hline 17 & 32,4 & 22,4 & 25,5 & 79 & 9 & 0,0 & 6,1 \\
\hline 18 & 30,2 & 21,7 & 24,1 & 86 & 9 & 4,9 & 2,7 \\
\hline 19 & 31,9 & 21,4 & 25,4 & 77 & 3 & 36,4 & 11,0 \\
\hline 20 & 32,0 & 21,9 & 25,5 & 79 & 9 & 0,0 & 4,6 \\
\hline 21 & 26,9 & 20,9 & 23,8 & 84 & 8 & 14,0 & 0,1 \\
\hline 22 & 29,3 & 20,4 & 24,3 & 87 & 7 & 0,0 & 7,9 \\
\hline 23 & 30,0 & 21,9 & 25,3 & 80 & 7 & 7,1 & 7,6 \\
\hline 24 & 31,0 & 21,8 & 26,1 & 80 & 7 & 0,0 & 10,3 \\
\hline 25 & 29,7 & 22,6 & 25,5 & 82 & 10 & 0,0 & 3,2 \\
\hline 26 & 30,4 & 22,2 & 24,7 & 85 & 7 & 0,3 & 4,8 \\
\hline 27 & 29,3 & 21,5 & 23,8 & 89 & 6 & 2,2 & 2,7 \\
\hline 28 & 31,3 & 21,1 & 25,5 & 77 & 2 & 25,7 & 11,7 \\
\hline 29 & 32,2 & 19,5 & 26,2 & 69 & 3 & 0,0 & 11,2 \\
\hline 30 & 33,6 & 21,7 & 27,4 & 62 & 3 & 0,0 & 11,9 \\
\hline 31 & 33,5 & 22,4 & 25,8 & 76 & 6 & 0,0 & 8,5 \\
\hline Total & & & & & & 257,7 & 207,1 \\
\hline Média & 31,1 & 21,5 & 25,3 & 80 & 6,7 & & \\
\hline
\end{tabular}

TM = temperatura média das máximas absolutas $\left({ }^{\circ} \mathrm{C}\right)$

$\mathrm{Tm}=$ temperatura média das mínimas absolutas $\left(O^{\circ}\right)$

$\mathrm{T}=$ temperatura média $\left({ }^{\circ} \mathrm{C}\right)$

$\mathrm{UR}=$ umidade relativa $(\%)$

$\mathrm{Ne}=$ nebulosidade (escala 0 - 10)

$\mathrm{P}=$ precipitação (mm)

In $=$ insolação (horas e décimos) 
TABEIA 20 - Dados meteorológicos diārios do mês de fevereiro de 1981.

\begin{tabular}{|c|c|c|c|c|c|c|c|}
\hline DIAS & $T M$ & $\operatorname{Tr}$ & $\mathrm{T}$ & UR & $\mathrm{Ne}$ & $\mathrm{P}$ & In \\
\hline 01 & 32,4 & 21,5 & 25,9 & 88 & 4 & 16,4 & 8,7 \\
\hline 02 & 31,6 & 21,9 & 26,1 & 84 & 6 & 25,0 & 6,4 \\
\hline 03 & 33,0 & 22,9 & 27,0 & 75 & 6 & 0,2 & 9,2 \\
\hline 04 & 34,0 & 21,8 & 26,1 & 78 & 7 & 0,0 & 9,6 \\
\hline 05 & 33,1 & 21,3 & 25,1 & 77 & 8 & 0,1 & 5,7 \\
\hline 06 & 33,4 & 20,4 & 24,9 & 77 & 7 & 0,3 & 8,2 \\
\hline 07 & 32,1 & 20,8 & 24,1 & 81 & 8 & 0,7 & 6,5 \\
\hline 08 & 33,3 & 21,1 & 26,6 & 72 & 4 & 0,0 & 9,3 \\
\hline 09 & 33,9 & 21,5 & 25,8 & 77 & 7 & 0,0 & 6,8 \\
\hline 10 & 34,2 & 20,2 & 25,9 & 70 & 4 & 1,4 & 10,0 \\
\hline 11 & 32,6 & 21,0 & 26,4 & 72 & 5 & 0,0 & 11,9 \\
\hline 12 & 31,8 & 21,4 & 25,4 & 88 & 7 & 0,0 & 5,5 \\
\hline 13 & 29,6 & 22,6 & 24,7 & 92 & 10 & 8,4 & 0,9 \\
\hline 14 & 30,7 & 19,9 & 24,0 & 80 & 7 & 3,6 & 7,0 \\
\hline 15 & 33,2 & 18,4 & 25,1 & 72 & 6 & 0,0 & 9,5 \\
\hline 16 & 33,9 & 20,5 & 26,5 & 65 & 5 & 0,7 & 11,3 \\
\hline 17 & 34,7 & 20,9 & 26,5 & 65 & 5 & 0,0 & 8,7 \\
\hline 18 & 34,3 & 19,9 & 26,8 & 60 & 2 & 0,0 & 10,7 \\
\hline 19 & 34,5 & 20,0 & 24,6 & 71 & 5 & 0,0 & 7,2 \\
\hline 20 & 26,5 & 19,8 & 22,6 & 86 & 10 & 32,8 & 2,4 \\
\hline 21 & 25,9 & 20,7 & 22,2 & 86 & 8 & 0,0 & 0,8 \\
\hline 22 & 27,7 & 18,8 & 22,5 & 82 & 9 & 1,5 & 3,6 \\
\hline 23 & 25,3 & 19,5 & 22,2 & 90 & 10 & 0,3 & 1,4 \\
\hline 24 & 31,1 & 18,9 & 23,7 & 78 & 7 & 1,2 & 4,9 \\
\hline 25 & 28,4 & 20,7 & 22,6 & 83 & 10 & 2,8 & 0,7 \\
\hline 26 & 31,6 & 20,0 & 24,5 & 75 & 5 & 3,0 & 6,5 \\
\hline 27 & 34,1 & 20,6 & 26,3 & 71 & 3 & 0,0 & 8,9 \\
\hline 28 & 33,2 & 20,8 & 25,6 & 81 & 2 & 0,0 & 7,1 \\
\hline Total & & & & & & 98,4 & 189,4 \\
\hline Média & 31,8 & 20,6 & 25,0 & 78 & 6,3 & & \\
\hline
\end{tabular}

$T M=$ temperatura média das máximas absolutas $\left({ }^{\circ} \mathrm{C}\right)$

$\mathrm{Tm}$ = temperatura média das mínimas absolutas $(\mathrm{OC})$

$\mathrm{T}=$ temperatura média $\left({ }^{\circ} \mathrm{C}\right)$

$\mathrm{UR}=$ umidade relativa $(\%)$

$\mathrm{Ne}=$ nebulosidade (escala $0-10)$

$\mathrm{P}=$ precipitação (mIt)

In = insolação (horas e décimos) 
TABELA 21 - Dados meteorológicos diārios do mês de março de 1981.

\begin{tabular}{|c|c|c|c|c|c|c|c|}
\hline DIAS & TM & Trn & $\mathrm{T}$ & UR & $\mathrm{Ne}$ & $\mathrm{P}$ & In \\
\hline 01 & 34,9 & 20,2 & 26,2 & 69 & 3 & 5,6 & 10,3 \\
\hline 02 & 34,3 & 21,6 & 27,6 & 67 & 6 & 0,0 & 8,7 \\
\hline 03 & 35,2 & 23,0 & 26,4 & 73 & 7 & 0,0 & 8,0 \\
\hline 04 & 32,1 & 20,8 & 25,4 & 76 & 8 & 9,0 & 3,2 \\
\hline 05 & 30,2 & 21,2 & 25,2 & 83 & 8 & 26,1 & 4,1 \\
\hline 06 & 31,7 & 21,2 & 24,9 & 87 & 7 & 0,1 & 5,6 \\
\hline 07 & 30,2 & 20,7 & 24,5 & 87 & 8 & 2,0 & 4,2 \\
\hline 08 & 30,6 & 20,7 & 24,6 & 87 & 8 & 0,0 & 5,4 \\
\hline 09 & 33,4 & 20,7 & 26,0 & 72 & 3 & 1,5 & 9,1 \\
\hline 10 & 34,6 & 19,9 & 25,7 & 64 & 5 & 0,0 & 10,3 \\
\hline 11 & 34,8 & 17,7 & 25,3 & 60 & 2 & 0,0 & 10,9 \\
\hline 12 & 34,3 & 16,4 & 25,0 & 57 & 2 & 0,0 & 11,0 \\
\hline 13 & 34,8 & 19,6 & 26,2 & 52 & 3 & 0,0 & 10,8 \\
\hline 14 & 34,6 & 18,6 & 26,3 & 66 & 5 & 0,0 & 7,9 \\
\hline 15 & 32,7 & 19,9 & 25,6 & 78 & 8 & 11,0 & 7,1 \\
\hline 16 & 29,8 & 20,3 & 23,2 & 95 & 10 & 0,0 & 1,7 \\
\hline 17 & 29,5 & 18,5 & 23,5 & 77 & 5 & 6,2 & 8,0 \\
\hline 18 & 31,1 & 17,6 & 24,0 & 76 & 6 & 0,0 & 6,3 \\
\hline 19 & 31,5 & 19,4 & 24,3 & 73 & 6 & 0,0 & 7,9 \\
\hline 20 & 32,3 & 19,5 & 25,7 & 67 & 4 & 0,0 & 10,2 \\
\hline 21 & 30,5 & 16,4 & 21,9 & 54 & 0 & 0,0 & 10,9 \\
\hline 22 & 31,3 & 14,7 & 22,6 & 67 & 1 & 0,0 & 10,6 \\
\hline 23 & 31,0 & 17,7 & 23,6 & 63 & 0,6 & 0,0 & 10,6 \\
\hline 24 & 31,9 & 17,4 & 23,9 & 63 & 3 & 0,0 & 9,7 \\
\hline 25 & 32,3 & 17,1 & 23,6 & 57 & 1 & 0,0 & 10,6 \\
\hline 26 & 32,1 & 18,0 & 25,0 & 68 & 6 & 0,0 & 8,8 \\
\hline 27 & 31,1 & 20,2 & 24,5 & 69 & 3 & 0,0 & 7,3 \\
\hline 28 & 29,4 & 19,2 & 24,0 & 72 & 3 & 0,0 & 6,7 \\
\hline 29 & 32,6 & 17,8 & 23,8 & 69 & 3 & 0,0 & 8,9 \\
\hline 30 & 31,5 & 16,7 & 22,9 & 63 & 0,6 & 0,0 & 10,2 \\
\hline 31 & 31,1 & 15,3 & 22,5 & 60 & 0 & 0,0 & 10,3 \\
\hline Total & & & & & & 61,5 & 255,3 \\
\hline Média & 32,2 & 19,0 & 24,6 & 68 & 44 & & \\
\hline
\end{tabular}

TM = temperatura média das máximas absolutas $\left({ }^{\circ} \mathrm{C}\right)$

Im = temperatura média das minimas absolutas ( $\left.{ }^{\circ} \mathrm{C}\right)$

$\mathrm{T}=$ temperatura média $\left(\mathrm{O}^{\circ}\right)$

$\mathrm{UR}=$ umidade relativa $(\%)$

$\mathrm{Ne}=$ nebulosidade (escala $0-10)$

$\mathrm{P}=$ precipitação (m)

In = insolação (horas e décimos) 